\title{
Formicins, $N$-Acetylcysteamine-Bearing Indenone Thioesters from a Wood Ant-Associated Bacterium
}

Young Eun Du, ${ }^{\dagger}$ Woong Sub Byun, ${ }^{\dagger}$ Seok Beom Lee ${ }^{\ddagger}$ Sunghoon Hwang, ${ }^{\dagger}$ Yern-Hyerk Shin, ${ }^{\dagger}$ Bora Shin, ${ }^{\dagger}$ Yong-Joon Jang, ${ }^{\S}$ Suckchang Hong, ${ }^{\dagger}$ Jongheon Shin, ${ }^{\dagger}$ Sang Kook Lee, ${ }^{\dagger}$ and Dong-Chan $\mathrm{Oh}^{*, \dagger}$

${ }^{\dagger}$ Natural Products Research Institute, College of Pharmacy, Seoul National University, Seoul 08826, Republic of Korea

${ }^{\ddagger}$ Research Institute of Pharmaceutical Science and College of Pharmacy, Seoul National University, Seoul 08826, Republic of Korea

$\S$ Natura center of Life and Environment, Seoul 08826, Republic of Korea

Correspondence to:

Prof. Dong-Chan Oh

Natural Products Research Institute,

College of Pharmacy,

Seoul National University, 1 Gwanak-ro, Gwanak-gu,

Seoul 08826, Republic of Korea

TEL: 82-2-880-2491; FAX: 82-2-762-8322; E-mail: dongchanoh@snu.ac.kr 
General experimental procedures

Collection and phylogenetic analysis of bacterial strain $\ldots \ldots \ldots \ldots \ldots \ldots \ldots . . . . . . . . . . . . .54$

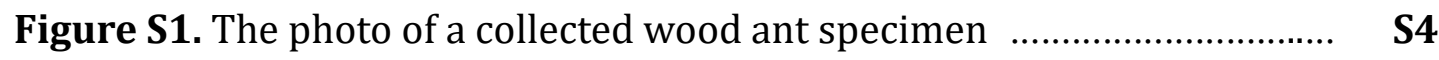

Cultivation and extraction

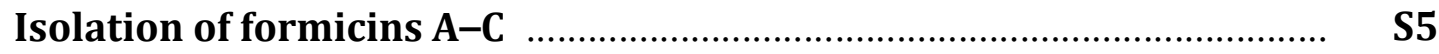

PGME derivatization of formicin C (3) …........................................... S6

Thioesterification of formicin C (3) ……............................................ S7

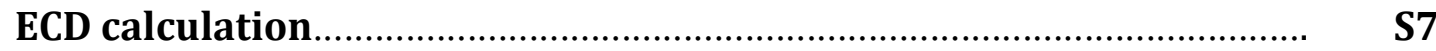

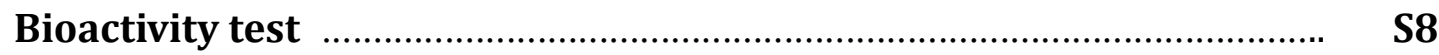

Figure S2. HR-MS/MS of formicins A and B (1 and 2).............................. S9

Figure S3. CD spectra of formicins A-C (1-3) and synthetic formicin B (2a) S9

Figure S4. Calculated and experimental ECD spectra of formicin C ............ $\quad \mathbf{S 1 0}$

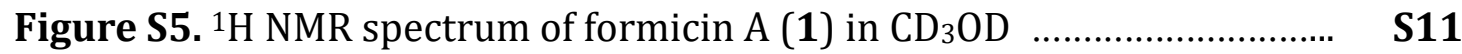

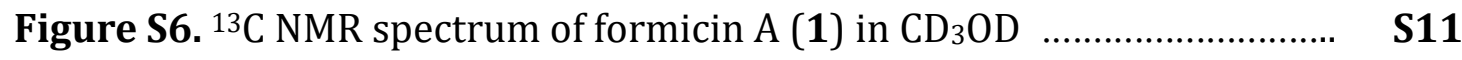

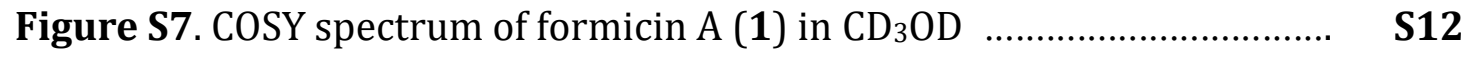

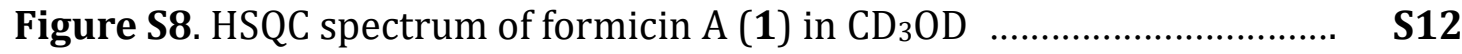

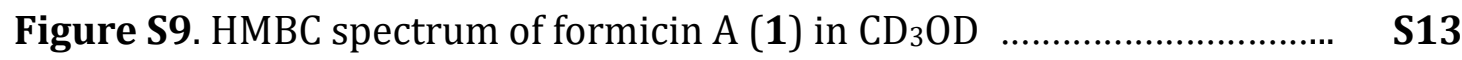

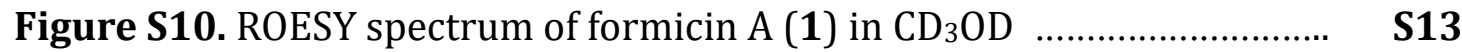

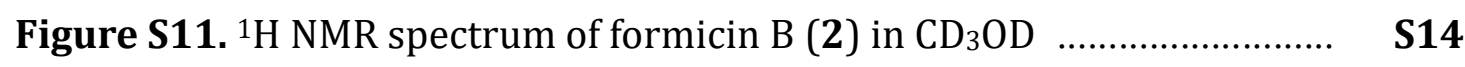

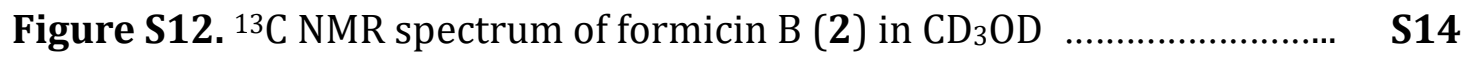

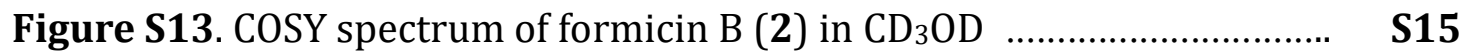

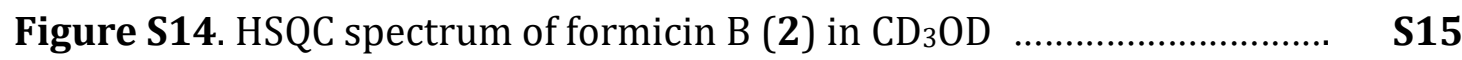

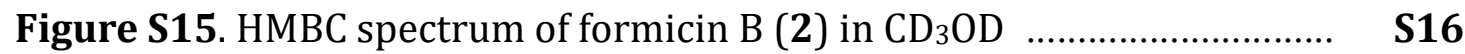

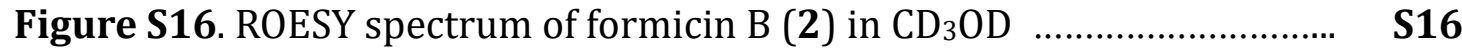

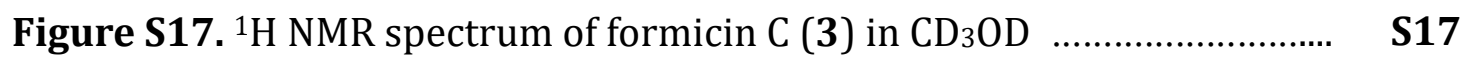

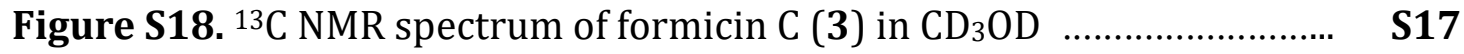

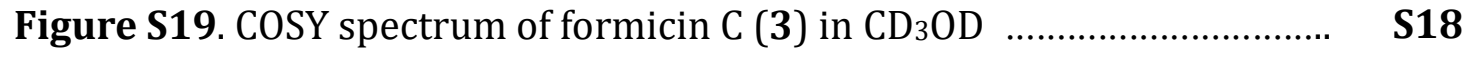




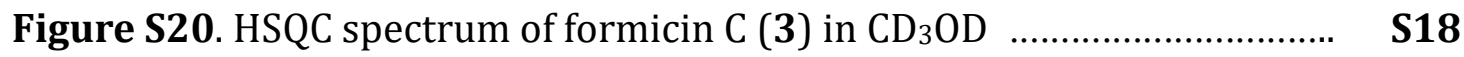

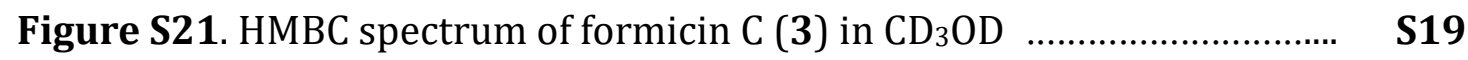

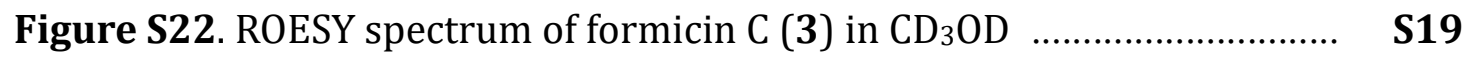

Figure S23. ${ }^{1} \mathrm{H}$ NMR spectrum of $S$-PGME amide (3a) of formicin C (3) ..... $\quad \mathbf{S 2 0}$

Figure S24. COSY spectrum of $S$-PGME amide (3a) of formicin C (3) ......... $\mathbf{S 2 0}$

Figure S25. ${ }^{1} \mathrm{H}$ NMR spectrum of $R$-PGME amide (3b) of formicin C (3) $\ldots . . \quad$ S21

Figure S26. COSY spectrum of $R$-PGME amide (3b) of formicin C (3) $\ldots \ldots \ldots . \quad$ S21

Figure S27. Key ROESY correlations of formicin C (3) ............................. S22

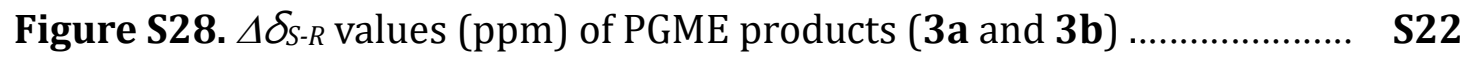

Figure S29. ${ }^{1} \mathrm{H}$ NMR spectrum of $\mathrm{N}$-acetylcysteamine in $\mathrm{CDCl}_{3} . \ldots \ldots \ldots \ldots \ldots \ldots . \quad \mathbf{S 2 3}$

Figure S30. ${ }^{13} \mathrm{C}$ NMR spectrum of $\mathrm{N}$-acetylcysteamine in $\mathrm{CDCl}_{3} \ldots \ldots \ldots \ldots \ldots . \quad \mathbf{S 2 3}$

Figure S31. ${ }^{1} \mathrm{H}$ NMR spectrum of synthetic formicin B (2a) in $\mathrm{CD}_{3} \mathrm{OD} \ldots \ldots \ldots . \quad$ S24

Figure S32. ${ }^{13} \mathrm{C}$ NMR spectrum of synthetic formicin $\mathrm{B}(\mathbf{2 a})$ in $\mathrm{CD}_{3} \mathrm{OD} \ldots \ldots \ldots . \quad \mathbf{S 2 4}$

Figure S33. COSY spectrum of synthetic formicin $\mathrm{B}(\mathbf{2 a})$ in $\mathrm{CD}_{3} \mathrm{OD} \quad \ldots \ldots \ldots \ldots \ldots . \quad \mathbf{S 2 5}$

Figure S34. HSQC spectrum of synthetic formicin B (2a) in $\mathrm{CD}_{3} \mathrm{OD} \quad \ldots \ldots \ldots \ldots \ldots . . \quad \mathbf{S 2 5}$

Figure S35. HMBC spectrum of synthetic formicin B (2a) in $\mathrm{CD}_{3} \mathrm{OD} \quad \ldots \ldots \ldots \ldots . \quad \mathbf{S 2 6}$

Figure S36. ROESY spectrum of synthetic formicin B (2a) in $\mathrm{CD}_{3} \mathrm{OD} \ldots \ldots \ldots \ldots . \quad$ S26

Figure S37. Comparison of ${ }^{1} \mathrm{H}$ NMR spectra of formicins $\mathrm{A}-\mathrm{B}(\mathbf{1}-\mathbf{2})$ and synthetic formicin $\mathrm{B}(\mathbf{2 a})$ at $800 \mathrm{MHz}$ in $\mathrm{CD}_{3} \mathrm{OD}$

Figure S38. Comparison of ${ }^{13} \mathrm{C}$ NMR spectra of formicins $\mathrm{A}-\mathrm{B}(\mathbf{1 - 2})$ and synthetic formicin $\mathrm{B}(\mathbf{2 a})$ at $200 \mathrm{MHz}$ in $\mathrm{CD}_{3} \mathrm{OD}$

Figure S39. HPLC chromatograms of isolated compounds (1, 2, 2a, 3, 3a, and 3b) (UV $280 \mathrm{~nm}$ )

Figure S40. Effect of formicin A (1) on the cell proliferation of MRC-5 cells (72 h incubation)

Table S1. Effect of formicin A-C (1-3) on the cell viability of breast cancer cells (MDA-MB-231) and human normal lung fibroblast cells (MRC-5)....... 


\section{General experimental procedures}

Optical rotations were measured by a JASCO P-2000 polarimeter (sodium light source, JASCO, Easton, PA, USA) with a 1-cm cell. UV spectra were acquired on a Chirascan plus Applied Photophysics spectrophotometer. IR spectra were obtained using a Thermo NICOLET iS10 spectrometer (Thermo, Madison, CT, USA). ${ }^{1} \mathrm{H},{ }^{13} \mathrm{C}$, and 2D NMR spectra were recorded on a Bruker Avance $800 \mathrm{MHz}$ spectrometer (Bruker, Billerica, MA, USA) at the Research Institute of Pharmaceutical Sciences in Seoul National University. ESI lowresolution LC/MS data were recorded using an Agilent Technologies 6130 Quadrupole mass spectrometer (Agilent Technologies, Santa Clara, CA, USA) coupled with an Agilent Technologies 1200 series high-performance liquid chromatography (HPLC) instrument using a reversed-phase $\mathrm{C}_{18}(2)$ column (Phenomenex Luna, $100 \times 4.6 \mathrm{~mm}$ ). HR-ESI mass spectra were acquired on a high-resolution LC/MSMS spectrometer (Q-TOF 5600) at the National Instrumentation Center for Environmental Management (NICEM) in the College of Agriculture and Life Sciences, Seoul National University.

\section{Collection and phylogenetic analysis of bacterial strain}

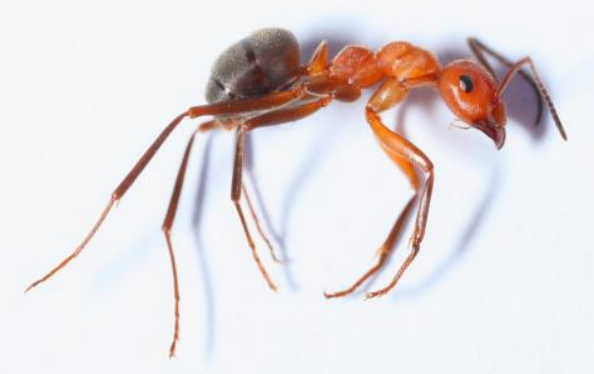

Figure S1. The photo of a collected wood ant specimen (Formica yessensis).

Ants were collected from a meadow near a sparse mixed forest (oak trees, Korean pine trees, shrubs, grass) in Cheongnyang Mountain, Gwangju-si, Gyeonggi-do, Republic of Korea in May 2018. All collected ants were worker-class and sterile females. These specimens, worker ants, were observed using a stereomicroscope (Olympus SZX16). The head, thorax, and petiole were yellowish red, and the gaster was black. The lateral view of the hind tibiae showed an internal margin with standing hairs, but an external margin without standing hairs. Based on their external morphological characteristics, the ant specimens were identified as wood ants, F. yessensis Wheeler, 1913 (Hymenoptera: Formicidae: Formicinae). Further field investigations in the studied area found that these wood ants, F. yessensis, lived in a nest mound located under a small (approximately $1 \mathrm{~m}$ high) oak tree. Witnessed foraging activities of the worker ants included collection of honey-dew from aphids (Hemiptera) on the surrounding trees, and predation of soil insects. Fifty wood-ants were collected, washed with sterilized water, and then soaked in $97 \%$ ethanol to remove the microbes on their exoskeleton. The ground whole wood ant specimens were diluted with $40 \mathrm{~mL}$ sterilized water in a conical tube at $25^{\circ} \mathrm{C}$. After vortexing, 200- $\mu \mathrm{L}$ aliquots of the suspension were spread on the surfaces of various types of solid agar media. The wood-ant associated actinomycete strain SFA33 was isolated from a modified $\mathrm{K}$ medium plate $(1 \mathrm{~L}$ distilled water, $4 \mathrm{~g}$ yeast extract, $5 \mathrm{~g}$ malt extract, 5 g soytone, $5 \mathrm{~g}$ soluble starch, $5 \mathrm{~g}$ mannitol, $2 \mathrm{~g}$ glucose), and it was identified as a 
Streptomyces sp. that is phylogenetically closest (99\% identity) to Streptomyces rochei (GenBank accession number AP018517) based on 16S rRNA gene sequence analysis (GenBank accession number MN826706).

\section{Cultivation and extraction}

The SFA33 strain was cultured in $50 \mathrm{~mL}$ modified K medium (4 g yeast extract, $5 \mathrm{~g}$ malt extract, 5 g soytone, 5 g soluble starch, 5 g mannitol, $2 \mathrm{~g}$ glucose, and 6 g glycerol in $1 \mathrm{~L}$ deionized water) in a $125 \mathrm{~mL}$ Erlenmeyer flask. After cultivation for 3 days on a rotary shaker at $200 \mathrm{rpm}$ and $30{ }^{\circ} \mathrm{C}, 5 \mathrm{~mL}$ of the culture medium was inoculated in $200 \mathrm{~mL}$ of modified $\mathrm{K}$ medium in a $500 \mathrm{~mL}$ Erlenmeyer flask. After cultivation for 3 days under the same incubation conditions, $10 \mathrm{~mL}$ of the culture medium was inoculated in $1 \mathrm{~L}$ of modified $\mathrm{K}$ medium in $2.8 \mathrm{~L}$ Fernbach flasks (200 ea $\times 1 \mathrm{~L}$ ) at $170 \mathrm{rpm}$ and $30{ }^{\circ} \mathrm{C}$ for 6 days. Two hundred liters of the SFA33 culture medium was extracted with $200 \mathrm{~L}$ of ethyl acetate. The ethyl acetate and water were separated, and the remaining water in the ethyl acetate was removed by adding anhydrous sodium sulfate. The ethyl acetate was removed using a rotary evaporator, yielding $35 \mathrm{~g}$ of dry extract.

\section{Isolation of formicins A-C}

The crude extract was chromatographed over a $\mathrm{C}_{18}$ reversed-phase open column, eluting with $20,40,60,80$, and $100 \% \mathrm{MeOH}-\mathrm{H}_{2} \mathrm{O}$ to afford five fractions. The $80 \% \mathrm{MeOH}-$ $\mathrm{H}_{2} \mathrm{O}$ fraction was injected directly into a preparative reversed-phase HPLC (Phenomenex $\mathrm{C}_{18}$ (2) Luna, $10 \mu \mathrm{m}, 250 \times 21.2 \mathrm{~mm}$, flow rate: $10 \mathrm{~mL} / \mathrm{min}$, detection: $\mathrm{UV}=210 \mathrm{~nm}$ ) using a gradient solvent system from $35 \%$ to $55 \% \mathrm{CH}_{3} \mathrm{CN}-\mathrm{H}_{2} \mathrm{O}$ over $40 \mathrm{~min}$, followed by a $55 \%$ $\mathrm{CH}_{3} \mathrm{CN}-\mathrm{H}_{2} \mathrm{O}$ isocratic solvent system for 40-60 min. Formicins A-C (1-3) were isolated at 47, 42, and $40 \mathrm{~min}$, respectively. They were further purified on a reversed-phase HPLC column (Kromasil $\mathrm{C}_{18}, 5 \mu \mathrm{m}, 250 \times 10 \mathrm{~mm}$ ) using isocratic conditions $\left(70 \% \mathrm{MeOH}-\mathrm{H}_{2} \mathrm{O}\right.$, UV detection at $280 \mathrm{~nm}$, flow rate: $2 \mathrm{~mL} / \mathrm{min}$ ) to yield, 1 ( $\mathrm{t}_{\mathrm{R}} 42 \mathrm{~min}, 3.7 \mathrm{mg}$ ), 2 ( $\mathrm{t}_{\mathrm{R}} 40 \mathrm{~min}$, $3.8 \mathrm{mg}$ ), and 3 ( $\mathrm{t}_{\mathrm{R}} 37 \mathrm{~min}, 4.1 \mathrm{mg}$ ).

Formicin A (1): white powder; $[\alpha]_{\mathrm{D}}{ }^{20}-103.6\left(c\right.$ 0.1, MeOH); UV (MeOH) $\lambda_{\max }(\log \varepsilon) 279$ (2.87) $\mathrm{nm}$; IR (neat) $v_{\max } 3733,1693 \mathrm{~cm}^{-1} ;{ }^{1} \mathrm{H},{ }^{13} \mathrm{C}$ and 2D-NMR (800 MHz, CD $\left.{ }_{3} \mathrm{OD}\right), \mathrm{HR}-$ ESI-MS $\mathrm{m} / \mathrm{z}$ : $[\mathrm{M}+\mathrm{Na}]^{+}$Calcd for $\mathrm{C}_{21} \mathrm{H}_{29} \mathrm{NO}_{3} \mathrm{SNa}, 398.1760$; Found 398.1761. ${ }^{1} \mathrm{H}$ NMR $(\mathrm{CD} 3 \mathrm{OD}, 800 \mathrm{MHz}) \delta_{\mathrm{H}} 6.67(1 \mathrm{H}, \mathrm{d}, J=9.9 \mathrm{~Hz}), 6.15(1 \mathrm{H}, \mathrm{dd}, J=9.9,5.9 \mathrm{~Hz}), 5.90(1 \mathrm{H}, \mathrm{d}, J=$ $1.8 \mathrm{~Hz}), 5.25(1 \mathrm{H}, \mathrm{dq}, J=9.2,0.9 \mathrm{~Hz}), 3.65(1 \mathrm{H}, \mathrm{dd}, J=9.2,5.9 \mathrm{~Hz}), 3.38(1 \mathrm{H}, \mathrm{m}), 3.30(2 \mathrm{H}$, td, $J=6.5,1.0 \mathrm{~Hz}), 3.13(1 \mathrm{H}, \mathrm{br} \mathrm{d}, J=5.2 \mathrm{~Hz}), 2.98(2 \mathrm{H}, \mathrm{m}), 2.57(1 \mathrm{H}, \mathrm{dd}, J=18.2,6.8 \mathrm{~Hz})$, $2.24(1 \mathrm{H}, \mathrm{dd}, J=18.2,4.1 \mathrm{~Hz}), 2.08(2 \mathrm{H}, \mathrm{t}, J=7.7 \mathrm{~Hz}), 1.89(3 \mathrm{H}, \mathrm{s}), 1.82(3 \mathrm{H}, \mathrm{d}, J=0.9 \mathrm{~Hz})$, $1.44(2 \mathrm{H}, \mathrm{tt}, J=7.7,7.5 \mathrm{~Hz}), 1.32(2 \mathrm{H}, \mathrm{m}), 0.93(3 \mathrm{H}, \mathrm{t}, J=7.4 \mathrm{~Hz}),{ }^{13} \mathrm{C}$ NMR $\left(200 \mathrm{MHz}, \mathrm{CD}_{3} \mathrm{OD}\right)$ $\delta_{\mathrm{c}} 210.7,199.3,173.6,173.5,141.1,140.7,126.5,123.5,123.5,56.7,40.7,40.4,40.0,39.9$, $37.3,31.2,29.4,23.4,22.5,16.7,14.3$

Formicin B (2): white powder; $[\alpha]_{\mathrm{D}^{20}}-83.1$ (c 0.1, MeOH); UV (MeOH) $\lambda_{\max }(\log \varepsilon) 281$ (2.87) nm; IR (neat) $v_{\max } 3287,1699 \mathrm{~cm}^{-1} ;{ }^{1} \mathrm{H},{ }^{13} \mathrm{C}$ and 2D-NMR (800 MHz, CD $\left.{ }_{3} \mathrm{OD}\right), \mathrm{HR}-$ ESI-MS m/z: $[\mathrm{M}+\mathrm{Na}]^{+}$Calcd for $\mathrm{C}_{21} \mathrm{H}_{29} \mathrm{NO}_{3} \mathrm{SNa}, 398.1760$; Found 398.1776. ${ }^{1} \mathrm{H}$ NMR $\left(\mathrm{CD}_{3} \mathrm{OD}, 800 \mathrm{MHz}\right) \delta_{\mathrm{H}} 6.63(1 \mathrm{H}, \mathrm{d}, J=9.6 \mathrm{~Hz}), 6.20(1 \mathrm{H}, \mathrm{dd}, J=9.6,5.6 \mathrm{~Hz}), 5.93(1 \mathrm{H}, \mathrm{d}, J=$ $1.9 \mathrm{~Hz}), 5.04(1 \mathrm{H}, \mathrm{dq}, J=10.2,1.1 \mathrm{~Hz}), 3.88(1 \mathrm{H}, \mathrm{ddd}, J=10.2,5.6,5.4 \mathrm{~Hz}), 3.48(1 \mathrm{H}, \mathrm{m})$, $3.27(2 \mathrm{H}, \mathrm{td}, J=7.0,2.6 \mathrm{~Hz}), 3.16(1 \mathrm{H}, \mathrm{dd}, J=12.7,5.4 \mathrm{~Hz}), 2.99(2 \mathrm{H}, \mathrm{m}), 2.72(1 \mathrm{H}, \mathrm{dd}, J=$ 18.2, $6.4 \mathrm{~Hz}), 2.06(1 \mathrm{H}, \mathrm{dd}, J=18.2,4.0 \mathrm{~Hz}), 2.00(2 \mathrm{H}, \mathrm{t}, J=7.4 \mathrm{~Hz}), 1.92(3 \mathrm{H}, \mathrm{s}), 1.73(3 \mathrm{H}$, $\mathrm{d}, J=1.1 \mathrm{~Hz}), 1.36(2 \mathrm{H}, \mathrm{tt}, J=7.5,7.4 \mathrm{~Hz}), 1.26(2 \mathrm{H}, \mathrm{m}), 0.90(3 \mathrm{H}, \mathrm{t}, J=7.4 \mathrm{~Hz}),{ }^{13} \mathrm{C}$ NMR 
Formicin C (3): white powder; $[\alpha]_{\mathrm{D}}{ }^{20}-379.9\left(c\right.$ 0.1, MeOH); UV (MeOH) $\lambda_{\max }(\log \varepsilon) 280$ (3.15) nm; IR (neat) $v_{\max } 3674,1707 \mathrm{~cm}^{-1} ;{ }^{1} \mathrm{H},{ }^{13} \mathrm{C}$ and 2D-NMR (800 MHz, CD ${ }_{3} \mathrm{OD}$ ), HRESI-MS m/z: $[\mathrm{M}+\mathrm{H}]^{+}$Calcd for $\mathrm{C}_{17} \mathrm{H}_{23} \mathrm{O}_{3}, 275.1641$; Found 275.1638. ${ }^{1} \mathrm{H}$ NMR $\left(\mathrm{CD}_{3} \mathrm{OD}, 800\right.$ MHz) $\delta_{\text {н }} 6.62(1 \mathrm{H}, \mathrm{d}, J=9.6 \mathrm{~Hz}), 6.24(1 \mathrm{H}, \mathrm{dd}, J=9.6,5.8 \mathrm{~Hz}), 5.90(1 \mathrm{H}, \mathrm{d}, J=1.9 \mathrm{~Hz}), 5.12$ $(1 \mathrm{H}, \mathrm{dq}, J=10.0,1.0 \mathrm{~Hz}), 3.83(1 \mathrm{H}, \mathrm{ddd}, J=10.0,5.8,5.4 \mathrm{~Hz}), 3.33(1 \mathrm{H}, \mathrm{m}), 2.81(1 \mathrm{H}, \mathrm{dd}, J$ $=18.6,6.3 \mathrm{~Hz}), 2.75(1 \mathrm{H}, \mathrm{dd}, J=13.0,5.4 \mathrm{~Hz}), 2.09(1 \mathrm{H}, \mathrm{dd}, J=18.6,4.0 \mathrm{~Hz}), 2.02(2 \mathrm{H}, \mathrm{t}, J$ $=7.4 \mathrm{~Hz}), 1.74(3 \mathrm{H}, \mathrm{d}, J=1.0 \mathrm{~Hz}), 1.40(2 \mathrm{H}, \mathrm{tt}, J=8.1,7.4 \mathrm{~Hz}), 1.29(2 \mathrm{H}, \mathrm{m}), 0.90(3 \mathrm{H}, \mathrm{t}, J=$ $7.3 \mathrm{~Hz}),{ }^{13} \mathrm{C}$ NMR $\left(200 \mathrm{MHz}, \mathrm{CD}_{3} \mathrm{OD}\right) \delta_{\mathrm{c}} 211.3,176.7,175.3,143.2,141.2,126.4,122.6$, $120.2,51.0,43.3,40.8,39.5,37.6,31.2,23.3,16.5,14.3$

\section{PGME derivatization of formicin C (3)}

Formicin C (1) (1.5 mg) was dissolved in $1 \mathrm{~mL}$ of dimethylformamide (DMF) and equal portions were transferred into two vials. The vials were treated with $3 \mathrm{mg}$ of benzotriazol1-yl-oxytripyrrolidino phosphonium hexafluorophosphate (PyBOP), $2 \mathrm{mg}$ of hydroxybenzotriazole (HOBt), and $100 \mu \mathrm{L}$ of 4-methylmorpholine. $S$-PGME reagent $(3 \mathrm{mg})$ was added to one vial, and $R$-PGME ( $3 \mathrm{mg}$ ) was added to the other. The reaction mixtures were stirred at room temperature for $1 \mathrm{~h}$, and the reactions were then quenched with $5 \%$ $\mathrm{HCl}$. After the reaction mixtures were dried in vacuo, the mixtures were purified on a reversed-phase HPLC column $\left(\mathrm{C}_{18}\right.$ Luna $10 \mu \mathrm{m} \mathrm{C}_{18}$ (2) $250 \mathrm{~mm} \times 21.2 \mathrm{~mm}, 10 \mathrm{~mL} / \mathrm{min}$, detection: UV at $210 \mathrm{~nm}$ ) with a gradient solvent system from $40 \%$ to $80 \% \mathrm{MeOH}-\mathrm{H}_{2} \mathrm{O}$ over $60 \mathrm{~min}$. The $S$ - and $R$-PGME products (3a and $\mathbf{3 b}$, respectively) of $\mathbf{3}$ eluted at $51 \mathrm{~min}$ and were white amorphous solids after drying. The weight of the reaction products was $0.7 \mathrm{mg}$ and $0.9 \mathrm{mg}$, and the reaction yields were $46.7-\%$ and $60.0-\%$, respectively. The molecular formula of the PGME products was determined to be $\mathrm{C}_{26} \mathrm{H}_{31} \mathrm{NO}_{4}$ by ESI-MS $(\mathrm{m} / \mathrm{z}$ : $\left.[\mathrm{M}+\mathrm{H}]^{+} 422.2\right)$. The $\Delta \delta s-R$ values of the products were calculated based on their ${ }^{1} \mathrm{H}$ and COSY NMR spectral data.

$S$-PGME product (3a, $0.6 \mathrm{mg}$ ): HR-ESI-MS $\mathrm{m} / \mathrm{z}$ : [M+H]+ Calcd for $\mathrm{C}_{26} \mathrm{H}_{32} \mathrm{NO}_{4}, 422.2326$; Found 422.2328. ${ }^{1} \mathrm{H}$ NMR $\left(\mathrm{CD}_{3} \mathrm{OD}, 800 \mathrm{MHz}\right) \delta_{\mathrm{H}} 7.35(5 \mathrm{H}, \mathrm{m}), 6.62(1 \mathrm{H}, \mathrm{d}, J=9.5 \mathrm{~Hz}), 6.22$ $(1 \mathrm{H}, \mathrm{dd}, J=9.5,6.0 \mathrm{~Hz}), 5.89(1 \mathrm{H}, \mathrm{d}, J=1.9 \mathrm{~Hz}), 5.52(1 \mathrm{H}, \mathrm{s}), 5.11(1 \mathrm{H}, \mathrm{d}, J=10.2 \mathrm{~Hz}), 3.84$ $(1 \mathrm{H}, \mathrm{m}), 3.69(3 \mathrm{H}, \mathrm{s}), 3.42(1 \mathrm{H}, \mathrm{m}), 2.83(1 \mathrm{H}, \mathrm{dd}, J=12.9,5.3 \mathrm{~Hz}), 2.68(1 \mathrm{H}, \mathrm{dd}, J=18.4,6.4$ $\mathrm{Hz}), 2.00(2 \mathrm{H}, \mathrm{t}, J=7.3 \mathrm{~Hz}), 1.91(1 \mathrm{H}, \mathrm{dd}, J=18.4,3.8 \mathrm{~Hz}), 1.73(3 \mathrm{H}, \mathrm{s}), 1.37(2 \mathrm{H}, \mathrm{m}), 1.28$ $(2 \mathrm{H}, \mathrm{m}), 0.92(3 \mathrm{H}, \mathrm{t}, J=7.3 \mathrm{~Hz})$

$R$-PGME product (3b, $0.9 \mathrm{mg}$ ): HR-ESI-MS $\mathrm{m} / \mathrm{z}$ : [M+H] ${ }^{+}$Calcd for $\mathrm{C}_{26} \mathrm{H}_{32} \mathrm{NO}_{4}, 422.2326$; Found 422.2322. ${ }^{1} \mathrm{H}$ NMR $\left(\mathrm{CD}_{3} \mathrm{OD}, 800 \mathrm{MHz}\right) \delta_{\mathrm{H}} 7.35(5 \mathrm{H}, \mathrm{m}), 6.61(1 \mathrm{H}, \mathrm{d}, J=9.6 \mathrm{~Hz}), 6.14$ $(1 \mathrm{H}, \mathrm{dd}, J=9.6,5.7 \mathrm{~Hz}), 5.91(1 \mathrm{H}, \mathrm{d}, J=1.9 \mathrm{~Hz}), 5.43(1 \mathrm{H}, \mathrm{s}), 5.04(1 \mathrm{H}, \mathrm{d}, J=10.0 \mathrm{~Hz}), 3.71$ $(3 \mathrm{H}, \mathrm{s}), 3.70(1 \mathrm{H}, \mathrm{m}), 3.40(1 \mathrm{H}, \mathrm{m}), 2.85(1 \mathrm{H}, \mathrm{dd}, J=12.7,5.8 \mathrm{~Hz}), 2.72(1 \mathrm{H}, \mathrm{dd}, J=18.3,6.4$ $\mathrm{Hz}), 2.04(1 \mathrm{H}, \mathrm{dd}, J=18.3,3.8 \mathrm{~Hz}), 1.89(2 \mathrm{H}, \mathrm{t}, J=7.8 \mathrm{~Hz}), 1.41(3 \mathrm{H}, \mathrm{s}), 1.26(2 \mathrm{H}, \mathrm{m}), 1.24$ $(2 \mathrm{H}, \mathrm{m}), 0.89(3 \mathrm{H}, \mathrm{t}, J=7.6 \mathrm{~Hz})$ 


\section{Thioesterification of formicin C (3)}

- Synthesis of $N$-acetylcysteamine

To a dry round bottomed flask was added cysteamine hydrochloride ( $3.0 \mathrm{~g}, 26.4 \mathrm{mmol}$, 1 equiv.), sodium bicarbonate ( $6.66 \mathrm{~g}, 79.2 \mathrm{mmol}, 3$ equiv.), potassium hydroxide $(1.48 \mathrm{~g}$, $26.4 \mathrm{mmol}, 1$ equiv.), and deionized water $(132 \mathrm{~mL})$. Acetic anhydride $(2.47 \mathrm{~mL}, 26.4$ mmol, 1 equiv.) was then added dropwise to the reaction mixture at $0{ }^{\circ} \mathrm{C}$, and was stirred at room temperature for $14 \mathrm{~h}$. After the reaction was completed, $1 \mathrm{M} \mathrm{HCl}$ was added to adjust the $\mathrm{pH}$ to 1.0. The mixture was extracted with EtOAc $(50 \mathrm{~mL} \times 5)$. The pooled organic phase was dried over $\mathrm{MgSO}_{4}$ and concentrated in vacuo. The residue was purified by flash column chromatography on silica gel, using hexane and EtOAc (1:3) as the eluent to afford $N$-acetylcysteamine $(2.73 \mathrm{~g})$ as a colorless oil at $87 \%$ yield. The ${ }^{1} \mathrm{H}$ NMR data of the obtained product exactly matched previously published data ${ }^{1}$; ${ }^{1} \mathrm{H}$ NMR $(400 \mathrm{MHz}$, $\left.\mathrm{CDCl}_{3}\right) \delta_{\mathrm{H}} 5.92(1 \mathrm{H}, \mathrm{s}), 3.43(2 \mathrm{H}, \mathrm{q}, J=6.3 \mathrm{~Hz}), 2.65-2.71(2 \mathrm{H}, \mathrm{m}), 2.01(3 \mathrm{H}, \mathrm{s}), 1.35(1 \mathrm{H}, \mathrm{t}$, $J=8.5 \mathrm{~Hz}),{ }^{13} \mathrm{C}$ NMR $\left(100 \mathrm{MHz}, \mathrm{CDCl}_{3}\right) \delta \mathrm{c} 170.7,42.5,24.3,23.0$; HR-FAB-MS $m / z:[\mathrm{M}+\mathrm{H}]^{+}$ Calcd for $\mathrm{C}_{4} \mathrm{H}_{10}$ NOS 120.0483; Found 120.0479 .

\section{- Synthesis of formicin B (2a)}

Formicin C (3, $2.0 \mathrm{mg}, 0.0073 \mathrm{mmol}, 1.0$ equiv.), $N$-(3-dimethylaminopropyl)- $N$ 'ethylcarbodiimide hydrochloride (1.57 $\mathrm{mg}, 0.0080 \mathrm{mmol}, 1.1$ equiv.), and 4(dimethylamino)pyridine $(0.45 \mathrm{mg}, 0.0036 \mathrm{mmol}, 0.5$ equiv.) were dissolved in $0.5 \mathrm{~mL}$ dichloromethane (DCM). The solution was cooled to $0{ }^{\circ} \mathrm{C}$ and then, $\mathrm{N}$-acetylcysteamine (1.74 mg, $0.0146 \mathrm{mmol}$, 2 equiv.) in DCM $(0.2 \mathrm{~mL})$ was added. The solution was warmed to room temperature and stirred for $3 \mathrm{~h}$. After addition of water $(1 \mathrm{~mL})$, the mixture was extracted with DCM $(2 \mathrm{~mL} \times 2)$. The pooled organic phase was dried over $\mathrm{MgSO}_{4}$ and concentrated in vacuo. ${ }^{2}$ The residue was purified on a reversed-phase HPLC column (Kromasil $\mathrm{C}_{18}, 5 \mu \mathrm{m}, 250 \times 10 \mathrm{~mm}$ ) using isocratic conditions $\left(70 \% \mathrm{MeOH}^{-\mathrm{H}_{2} \mathrm{O}, \mathrm{UV}}\right.$ detection at $280 \mathrm{~nm}$, flow rate: $2 \mathrm{~mL} / \mathrm{min}, \mathrm{t}_{\mathrm{R}} 40 \mathrm{~min}$ ) to afford synthetic formicin $\mathrm{B}$ (2a, $1.2 \mathrm{mg}$ ). The structure of the synthetic formicin B (2a) was confirmed by NMR, and it was identical to isolated formicin B (2).

Synthetic formicin B (2a): white powder; $[\alpha]_{\mathrm{D}^{20}}-88.0(c$ 0.05, $\mathrm{MeOH})$; UV (MeOH) $\lambda_{\max }$ $(\log \varepsilon) 280(3.17) \mathrm{nm}$; IR (neat) $v_{\max } 3336,1684 \mathrm{~cm}^{-1} ;{ }^{1} \mathrm{H},{ }^{13} \mathrm{C}$ and $2 \mathrm{D}-\mathrm{NMR}(800 \mathrm{MHz}$, $\mathrm{CD}_{3} \mathrm{OD}$ ), ESI-MS m/z: [M+Na] ${ }^{+}$Calcd for $\mathrm{C}_{21} \mathrm{H}_{29} \mathrm{NO}_{3} \mathrm{SNa}, 398.1,{ }^{1} \mathrm{H}$ NMR $\left(\mathrm{CD}_{3} \mathrm{OD}, 800 \mathrm{MHz}\right.$ ) $\delta_{\mathrm{H}} 6.63(1 \mathrm{H}, \mathrm{d}, J=9.6 \mathrm{~Hz}), 6.20(1 \mathrm{H}, \mathrm{dd}, J=9.6,5.6 \mathrm{~Hz}), 5.93(1 \mathrm{H}, \mathrm{d}, J=1.9 \mathrm{~Hz}), 5.04(1 \mathrm{H}$, $\mathrm{dq}, J=10.2,1.1 \mathrm{~Hz}), 3.88(1 \mathrm{H}, \mathrm{ddd}, J=10.2,5.6,5.4 \mathrm{~Hz}), 3.48(1 \mathrm{H}, \mathrm{m}), 3.27(2 \mathrm{H}, \mathrm{td}, J=7.0$, $2.6 \mathrm{~Hz}), 3.16(1 \mathrm{H}, \mathrm{dd}, J=12.7,5.4 \mathrm{~Hz}), 2.99(2 \mathrm{H}, \mathrm{m}), 2.72(1 \mathrm{H}, \mathrm{dd}, J=18.2,6.4 \mathrm{~Hz}), 2.06$ $(1 \mathrm{H}, \mathrm{dd}, J=18.1,4.0 \mathrm{~Hz}), 2.00(2 \mathrm{H}, \mathrm{t}, J=7.4 \mathrm{~Hz}), 1.92(3 \mathrm{H}, \mathrm{s}), 1.73(3 \mathrm{H}, \mathrm{d}, J=1.1 \mathrm{~Hz}), 1.36$ $(2 \mathrm{H}, \mathrm{tt}, J=7.5,7.4 \mathrm{~Hz}), 1.26(2 \mathrm{H}, \mathrm{m}), 0.90(3 \mathrm{H}, \mathrm{t}, J=7.3 \mathrm{~Hz}),{ }^{13} \mathrm{C}$ NMR (CD $\left.30 \mathrm{OD}, 200 \mathrm{MHz}\right) \delta_{\mathrm{c}}$ 210.4, 199.8, 174.3, 173.4, 142.1, 141.4, 126.9, 122.6, 119.5, 58.2, 42.2, 40.6, 40.6, 40.2, $37.1,31.1,28.8,23.2,22.5,16.7,14.3$.

\section{ECD calculation}

The possible isomers of compound $\mathbf{3}$ were modeled based on roesy data and the energyminimized isomer structures were generated by Avogadro 1.2.0. Energy minimization of the four isomer structures was performed by Turbomole X 4.3.2. The calculated ECD spectra corresponding to four isomer models were calculated using DFT at the functional B3LYP/DFT level and the def-SV(P) basis set. The ECD spectra were simulated by overlapping each transition, where $\sigma$ is the width of the band at $1 / e$ height. $\Delta E_{i}$ is the 
excitation energies and $R_{i}$ is rotatory strengths for transition $i$. In this calculation, the $\sigma$ value was at $0.10 \mathrm{eV}$. The observed ECD spectrum of compound 1-3 showed negative cotton effect around $279 \mathrm{~nm}$. Comparing with the calculated spectra of the four isomers with the measured ECD spectrum, the absolute configuration of compound $\mathbf{1}(2 S, 3 S, 10 S)$ and compound $\mathbf{2}$ and $\mathbf{3}(2 R, 3 S, 10 S)$ were clearly deduced.

$$
\Delta \epsilon(E)=\frac{1}{2.297 \times 10^{-39}} \frac{1}{\sqrt{2 \pi \sigma}} \sum_{i}^{A} \Delta E_{i} R_{i} e^{\left[-\left(E-\Delta E_{i}\right)^{2} /(2 \sigma)^{2}\right]}
$$

\section{Bioactivity test}

- Cell culture and chemicals

MDA-MB-231 human breast cancer cells and MRC-5 human normal lung fibroblast cells were obtained from the American Type Culture Collection (Manassas, VA, USA). The cells were cultured in Dulbecco's Modified Eagle's Medium supplemented with penicillinstreptomycin $(10,000$ units $/ \mathrm{mL}$ sodium penicillin $\mathrm{G}$ and $10,000 \mu \mathrm{g} / \mathrm{mL}$ streptomycin) and $10 \%$ fetal bovine serum in an incubator containing $5 \% \mathrm{CO}_{2}$ at $37{ }^{\circ} \mathrm{C}$. All reagents used for cell culture were purchased from Gibco ${ }^{\circledR}$ Invitrogen Corp. (Grand Island, NY, USA). The compounds were dissolved in $100 \%$ dimethyl sulfoxide.

\section{- Cell proliferation assay (SRB assay)}

Cell proliferation was measured using a sulforhodamine B (SRB) assay. ${ }^{3}$ Briefly, cells were seeded in 96-well plates and incubated for $30 \mathrm{~min}$ (for day 0 controls) or treated with test compounds for the indicated times. After incubation, the cells were fixed, dried, and stained with $0.4 \%$ SRB in $1 \%$ acetic acid solution. Unbound dye was removed by washing with $1 \%$ acetic acid, after which the stained cells were dissolved in $10 \mathrm{mM}$ Tris (pH 10.0). The absorbance of the cell solution was measured at $515 \mathrm{~nm}$, and this value was used to determine cell proliferation. IC $_{50}$ values were calculated by a nonlinear regression analysis with TableCurve 2D v5.01 software (Systant Software Inc., Richmond, CA, USA). All reagents used in the SRB assay were purchased from Sigma-Aldrich (St. Louis, MO, USA)

- Western blotting analysis

The expression levels of proteins were evaluated using western blot analysis as previously reported. ${ }^{4}$ Briefly, equal amounts of protein $(5-10 \mu \mathrm{g})$ were separated by $8-$ $12 \%$ SDS-polyacrylamide gel electrophoresis (PAGE) and transferred to polyvinylidene fluoride membranes (Millipore, Bedford, MA, USA). The membranes were blocked with 5\% bovine serum albumin (BSA, Sigma-Aldrich) and then probed with anti-phospho-LKB1

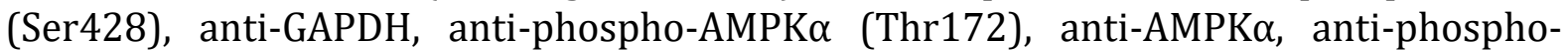
mTOR (Ser2448), anti-mTOR, anti-phospho-4E-BP-1 (Thr37/46), anti-Cyclin D1, anti-cMyc (Cell Signaling Technology, Beverly, MA, USA), or anti- $\beta$-Tubulin (Santa Cruz Biotechnology, Dallas, TX, USA) antibodies. The blots were detected using a WEST-Queen detection system (iNtRON Biotechnology, Seongnam, Republic of Korea). 
Figure S2. HR-MS/MS of formicins A and B (1 and 2).

(a) MS/MS spectrum of formicin A (1)

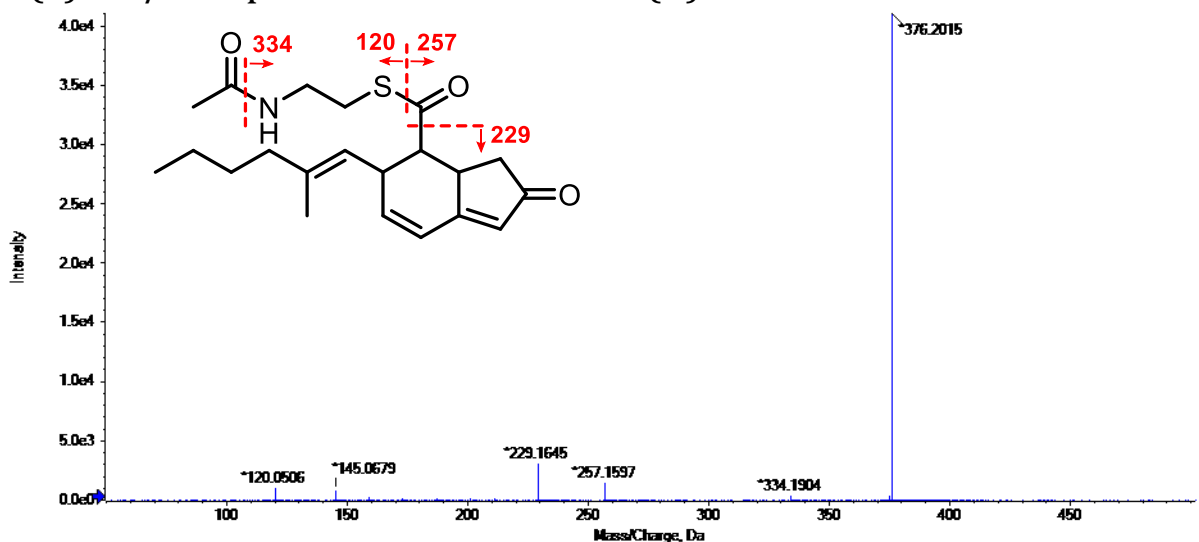

(b) MS/MS spectrum of formicin B (2)

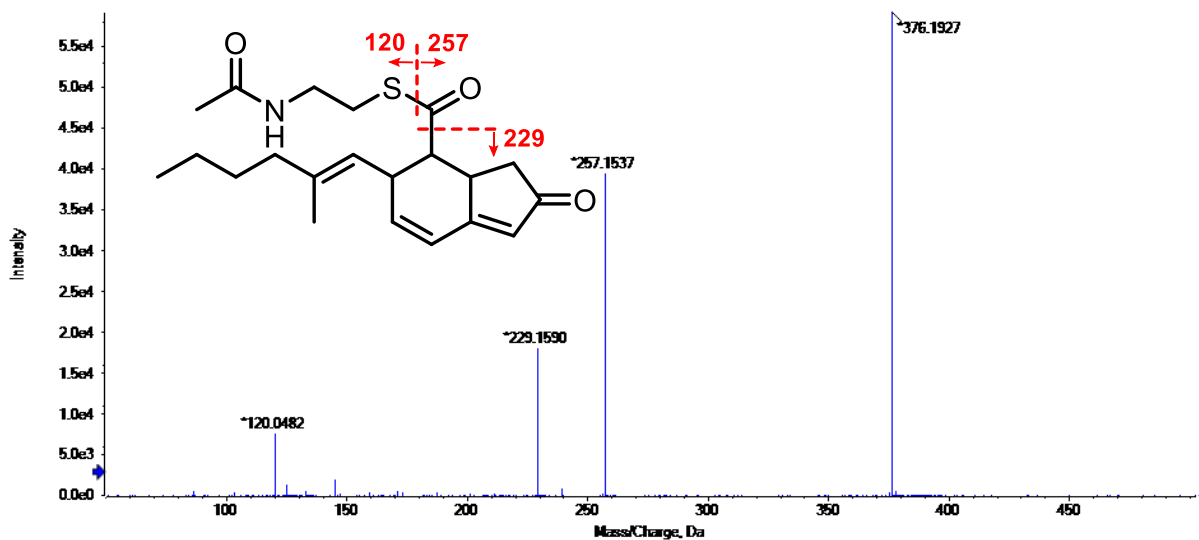

Figure S3. CD spectra of formicins A-C (1-3) and synthetic product (2a).
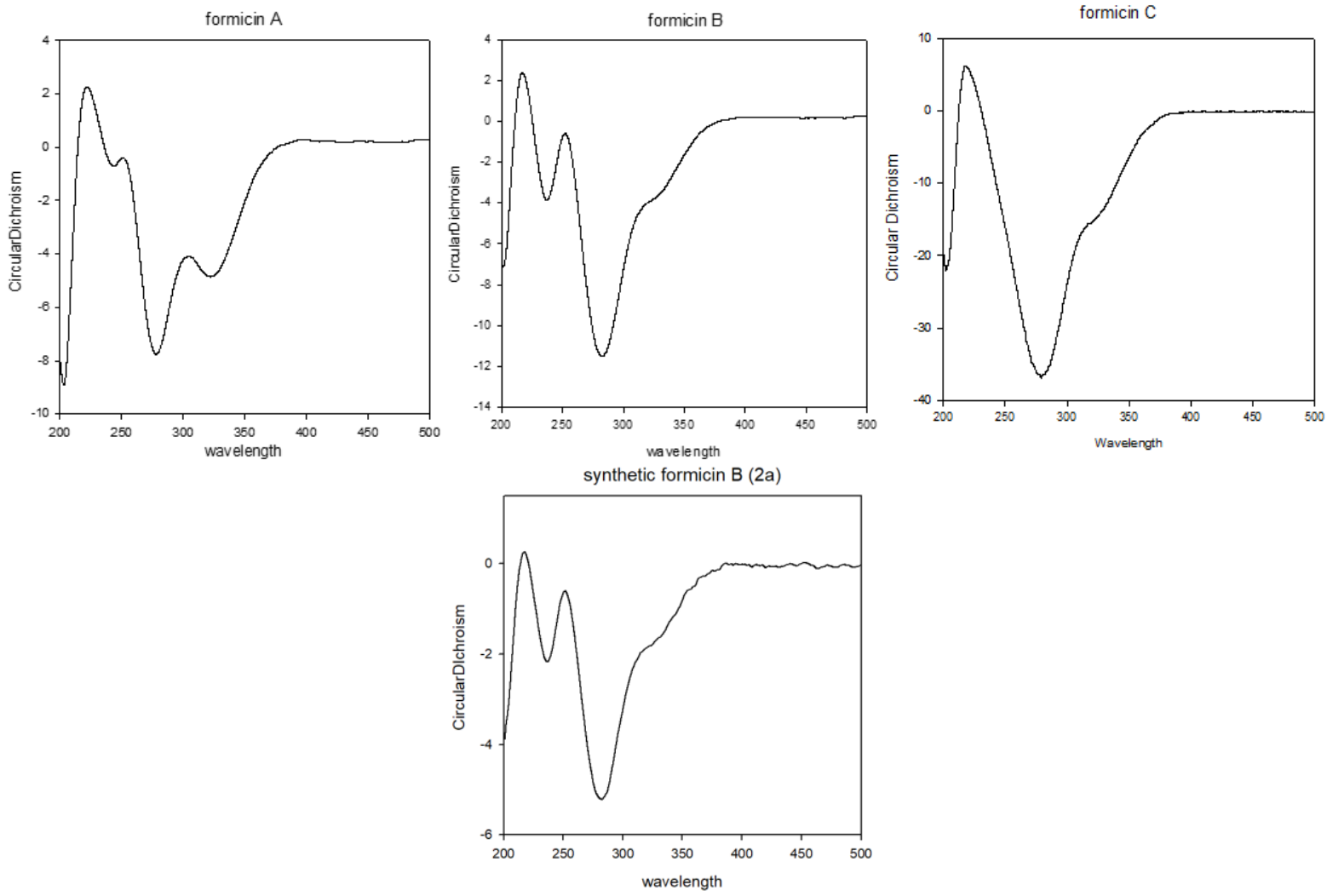
Figure S4. Calculated and experimental ECD spectra of formicin C (3).

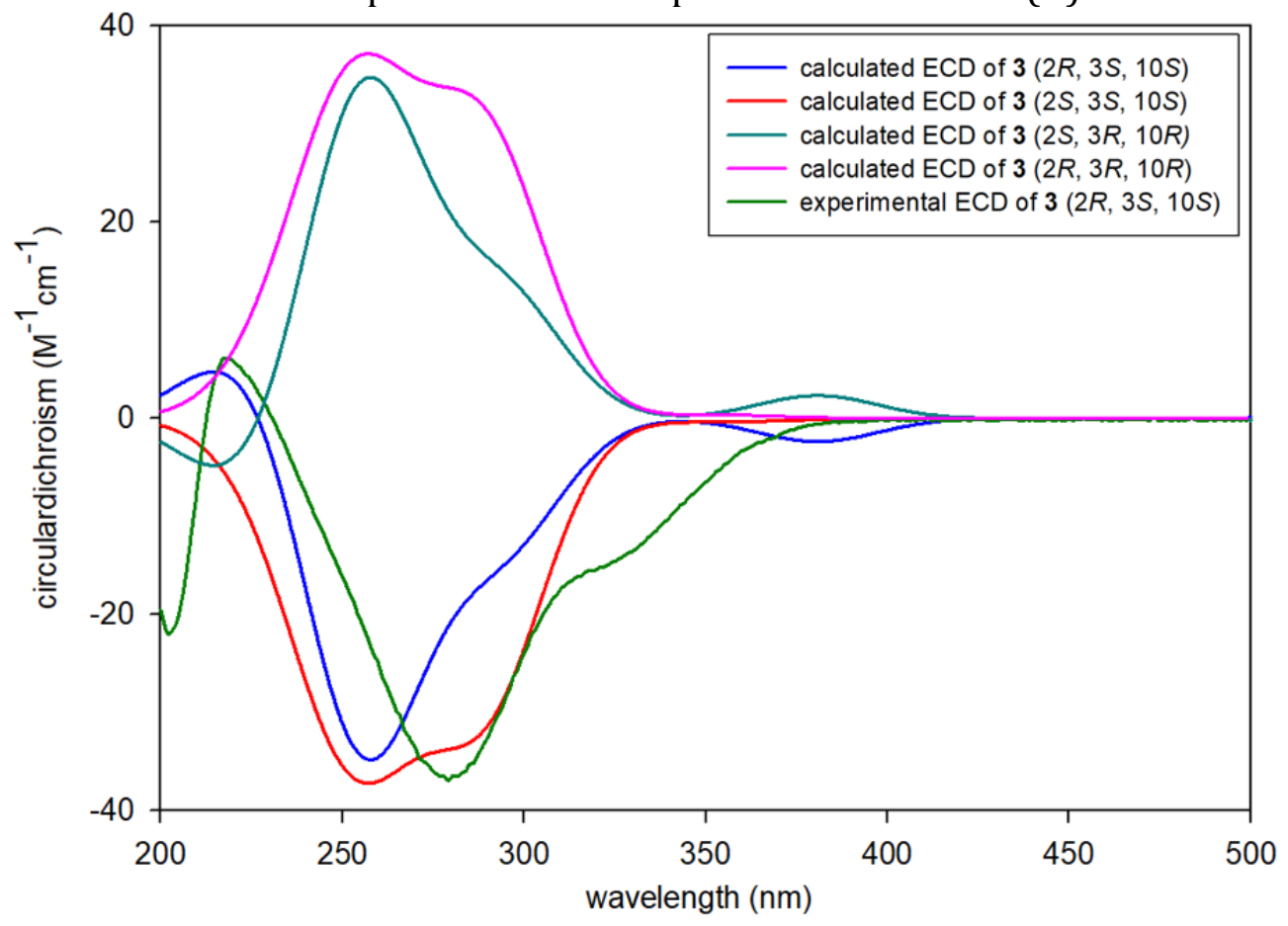

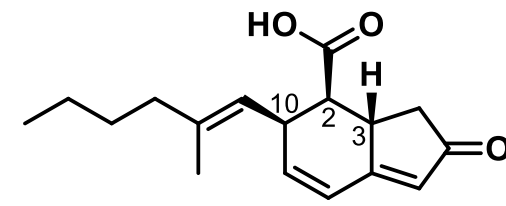

$2 R, 3 S, 10 S$

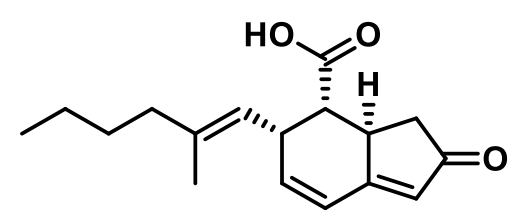

$2 S, 3 R, 10 R$

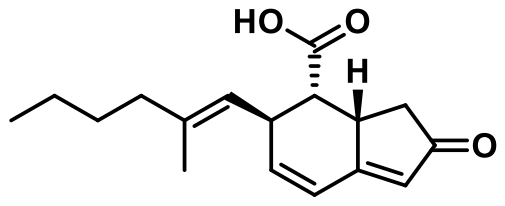

$2 S, 3 S, 10 S$<smiles>CCCC/C(C)=C/[C@H]1C=CC2=CC(=O)C[C@H]2C1C(=O)O</smiles>

$2 R, 3 R, 10 R$ 
Figure S5. ${ }^{1} \mathrm{H}$ NMR spectrum of formicin $\mathrm{A}(\mathbf{1})$ at $800 \mathrm{MHz}$ in $\mathrm{CD}_{3} \mathrm{OD}$.

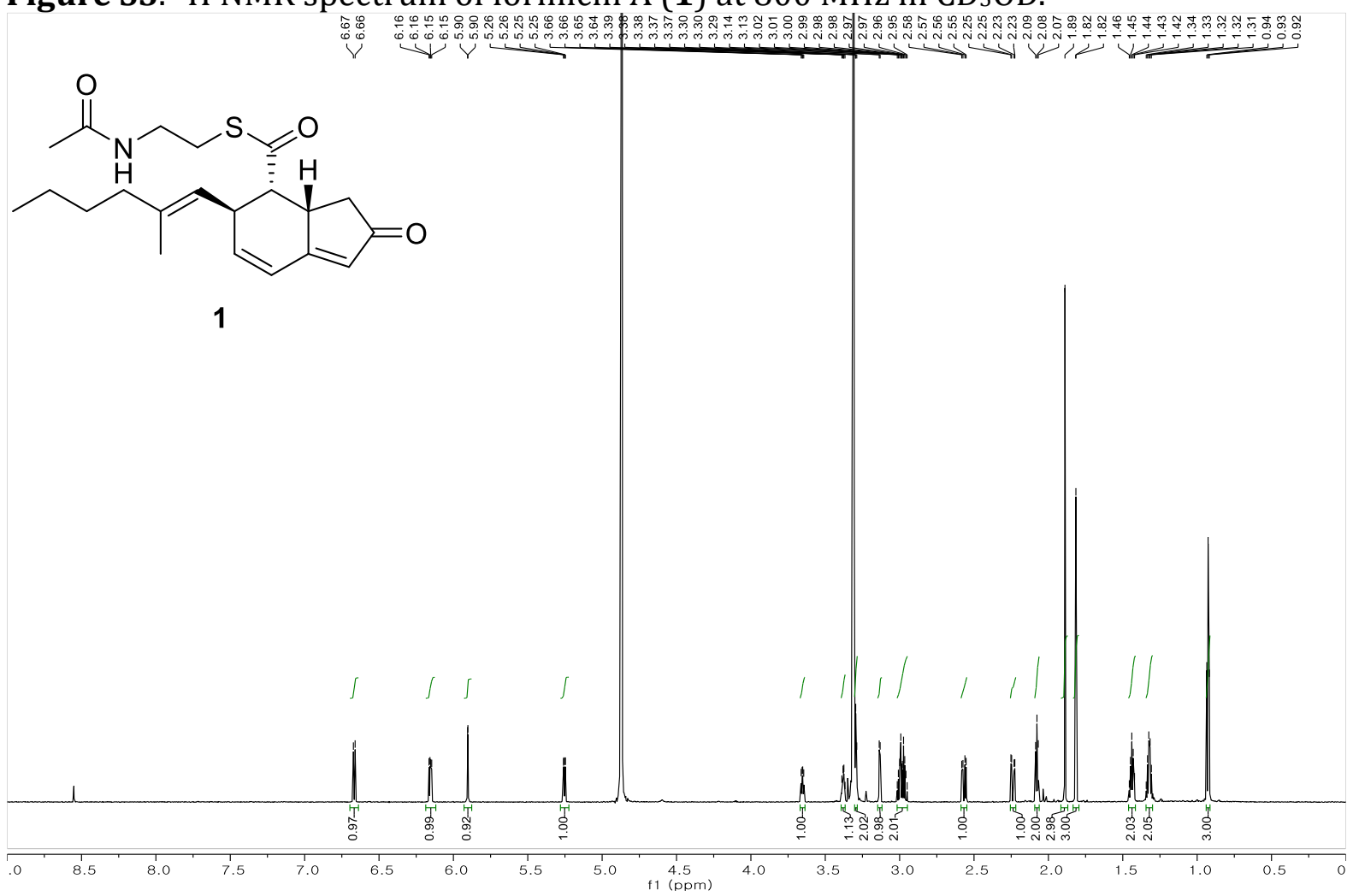

Figure S6. ${ }^{13} \mathrm{C}$ NMR spectrum of formicin $\mathrm{A}(\mathbf{1})$ at $200 \mathrm{MHz}$ in $\mathrm{CD}_{3} \mathrm{OD}$.

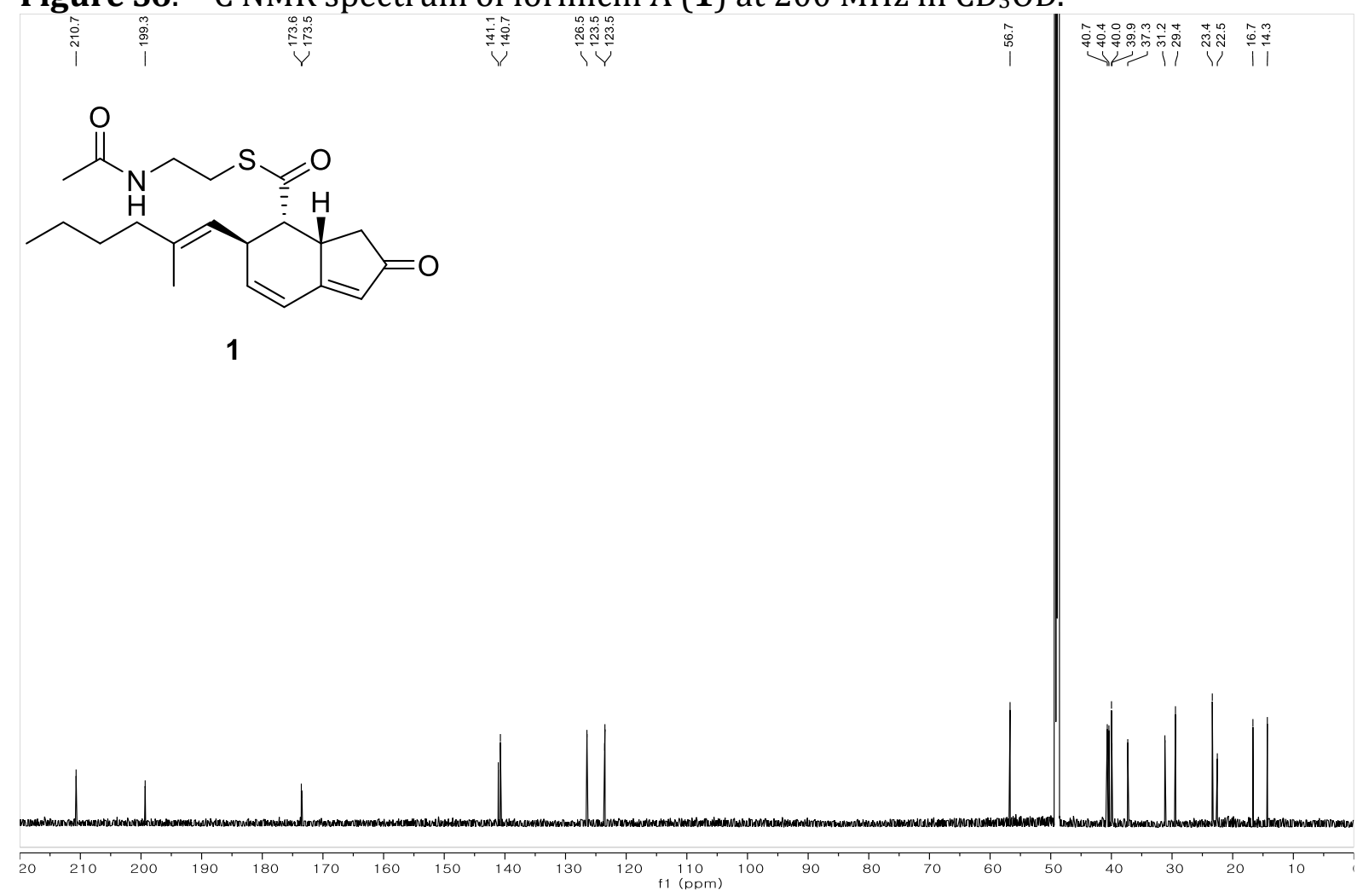


Figure S7. COSY spectrum of formicin A (1) at $800 \mathrm{MHz}$ in $\mathrm{CD}_{3} \mathrm{OD}$.

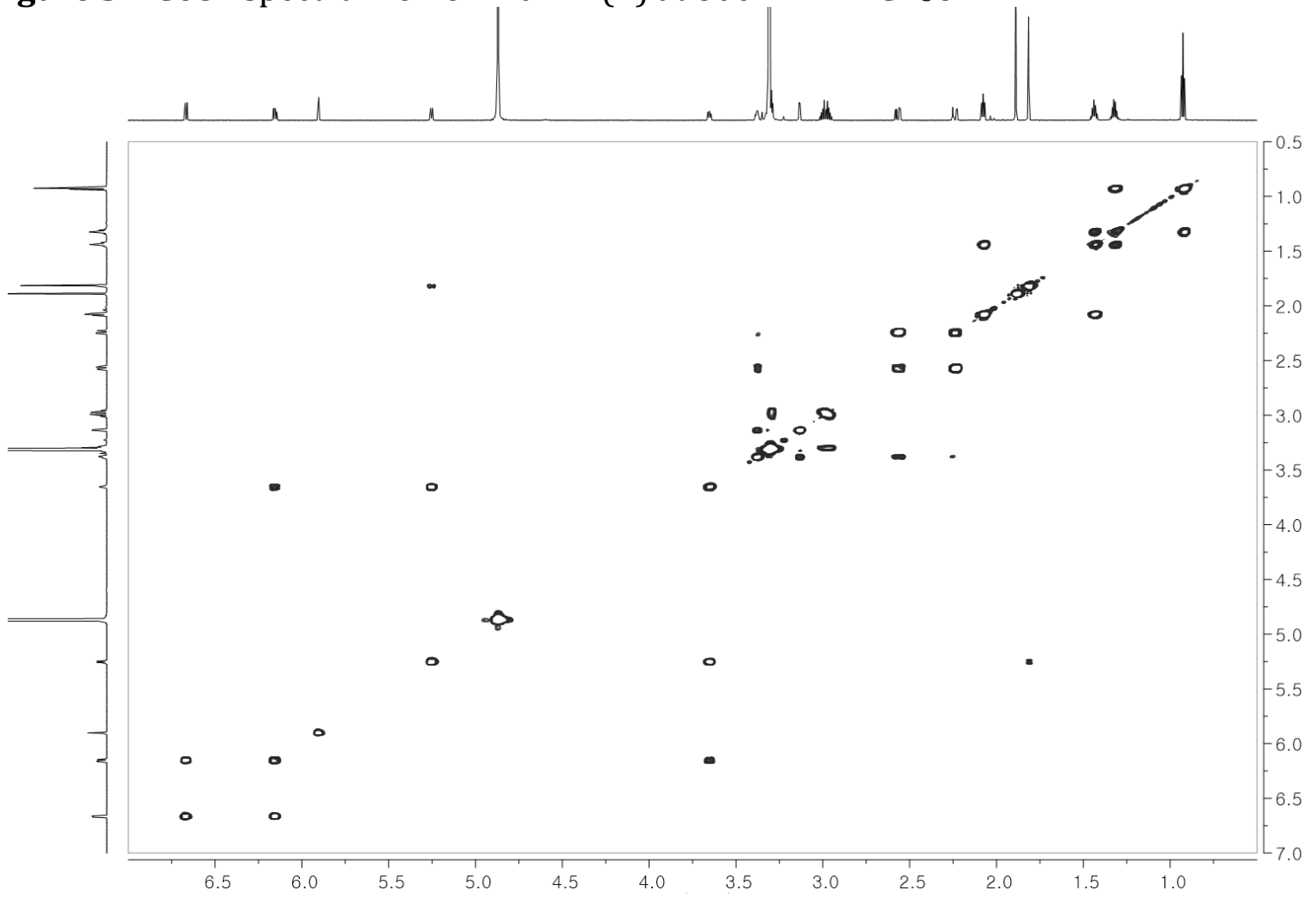

Figure S8. HSQC spectrum of formicin A (1) at $800 \mathrm{MHz}$ in $\mathrm{CD}_{3} \mathrm{OD}$.

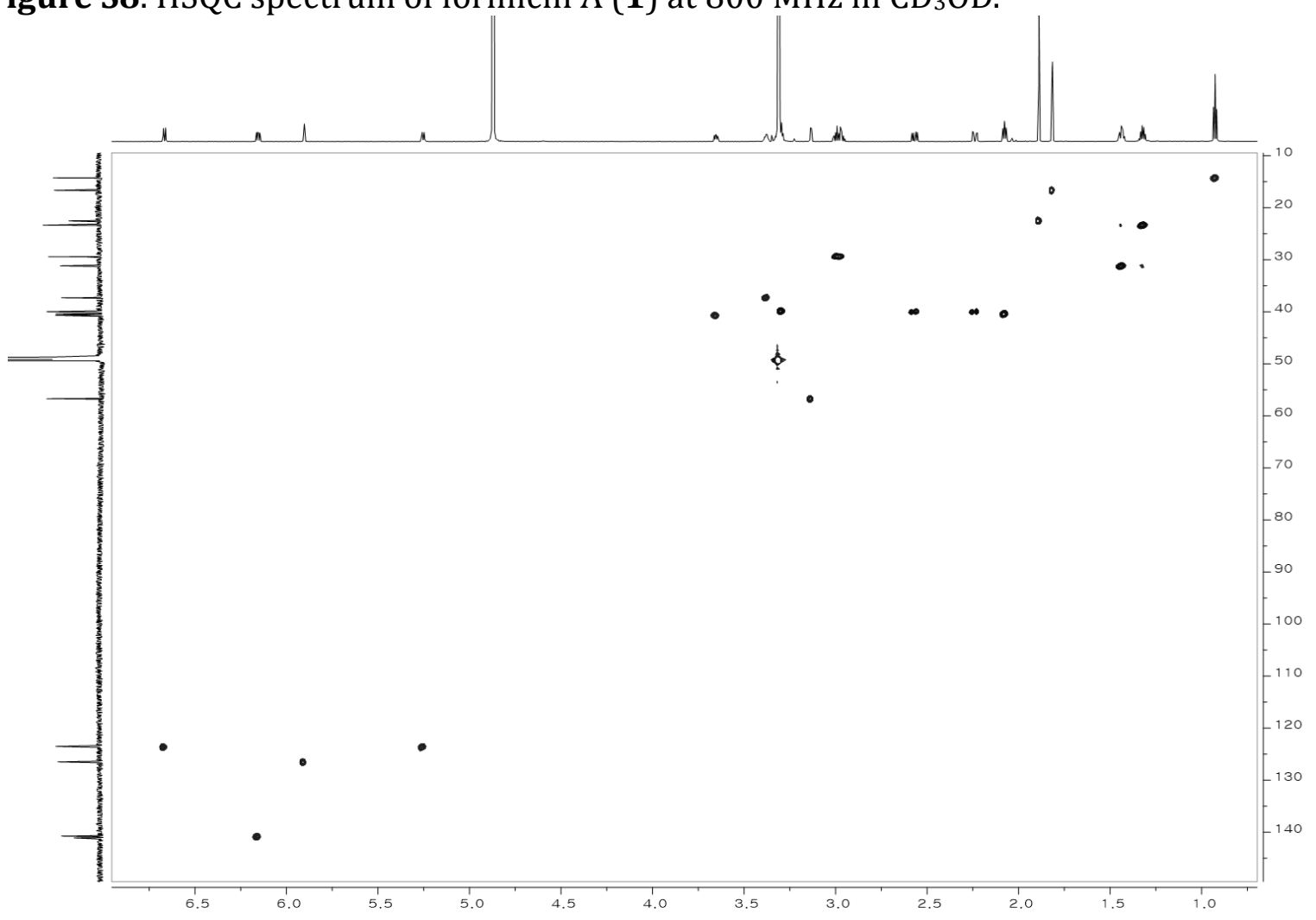


Figure S9. HMBC spectrum of formicin $\mathrm{A}(1)$ at $800 \mathrm{MHz}$ in $\mathrm{CD}_{3} \mathrm{OD}$.

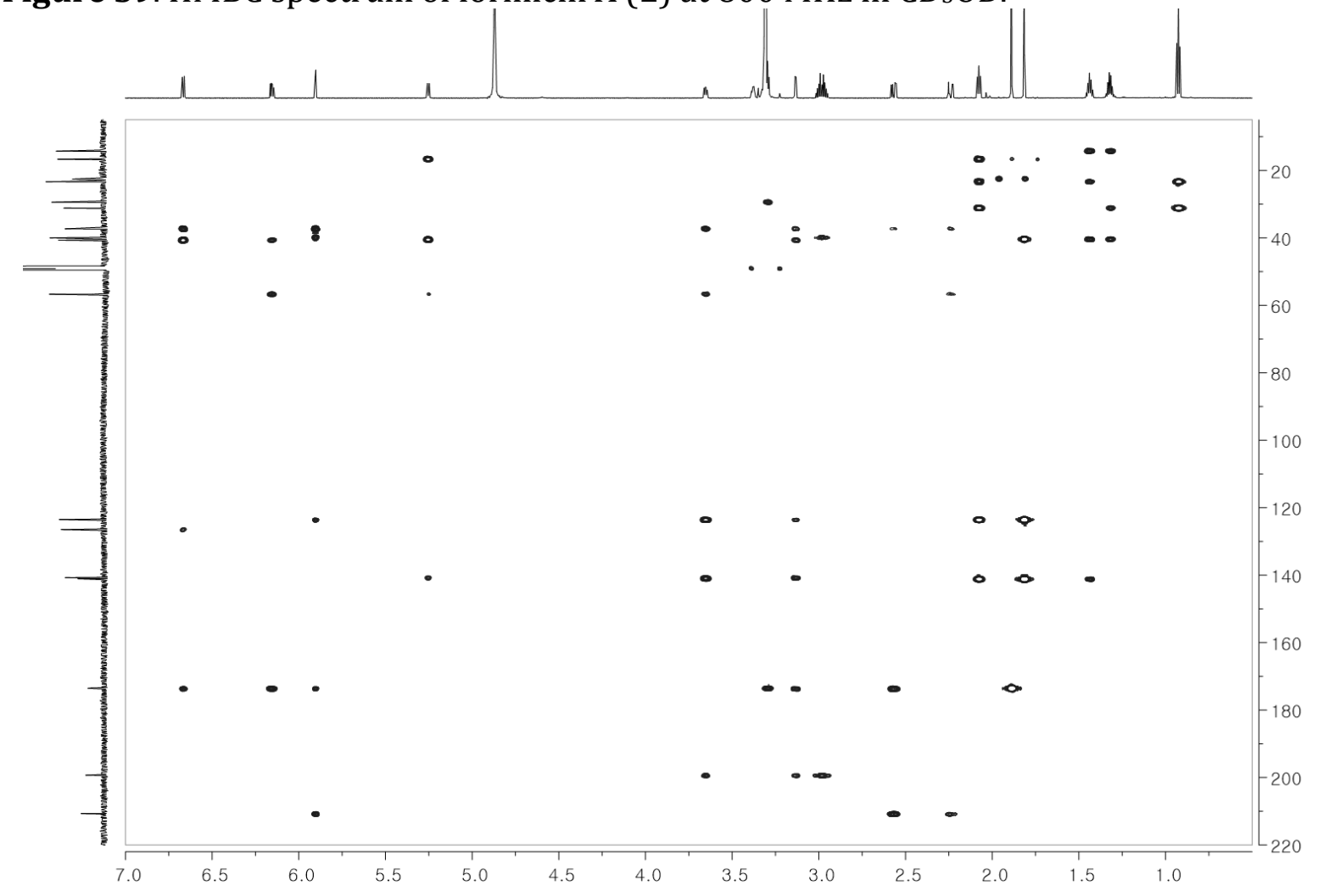

Figure S10. ROESY spectrum of formicin A (1) at $800 \mathrm{MHz}$ in $\mathrm{CD}_{3} \mathrm{OD}$.

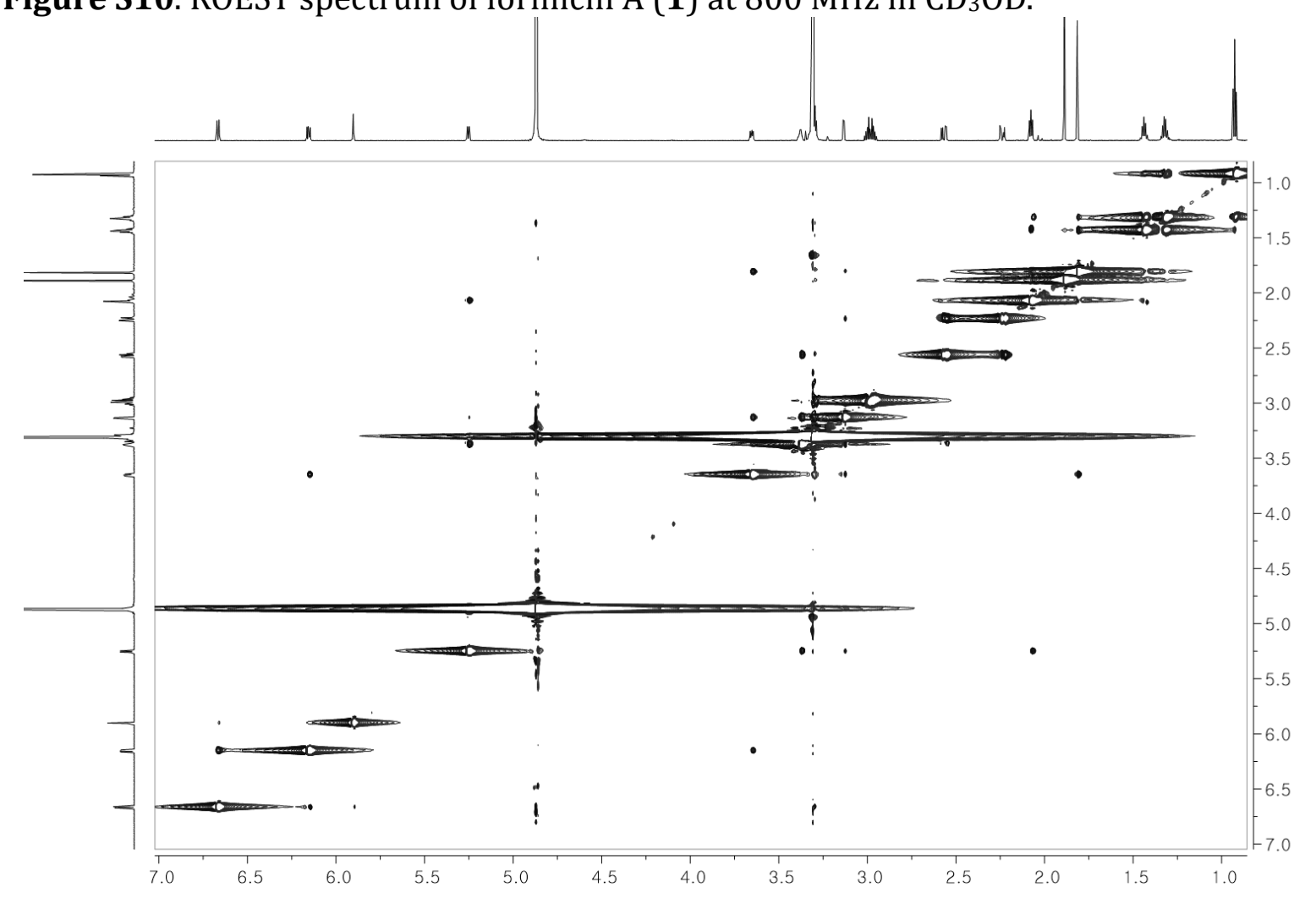


Figure S11. ${ }^{1} \mathrm{H}$ NMR spectrum of formicin $\mathrm{B}(2)$ at $800 \mathrm{MHz}$ in $\mathrm{CD}_{3} \mathrm{OD}$.

过骂<smiles>CCCC/C(C)=C/[C@H]1C=CC2=CC(=O)C[C@H]2C1C(=O)SCCNC(C)=O</smiles>

2

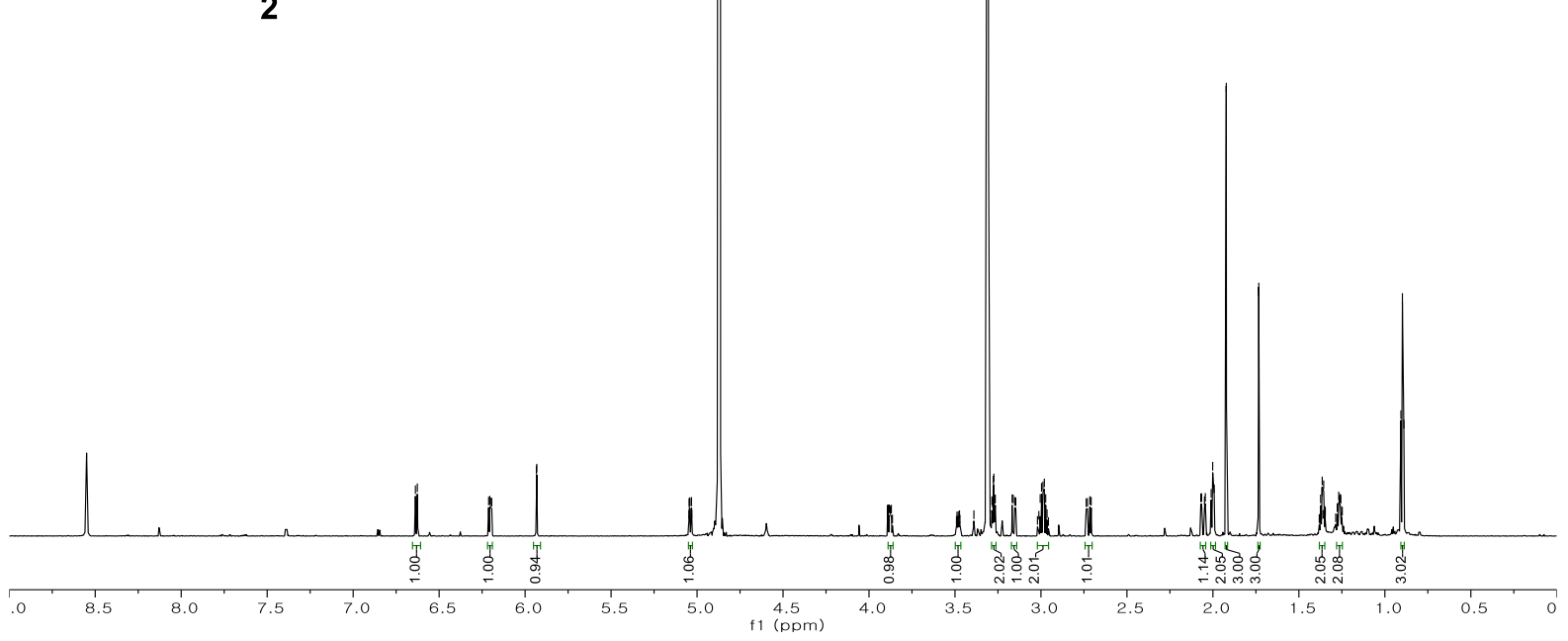

Figure S12. ${ }^{13} \mathrm{C}$ NMR spectrum of formicin B (2) at $200 \mathrm{MHz}$ in $\mathrm{CD}_{3} \mathrm{OD}$.

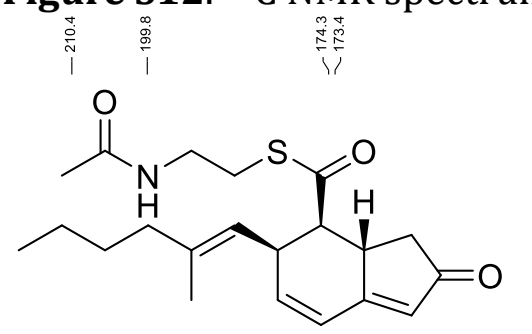

2

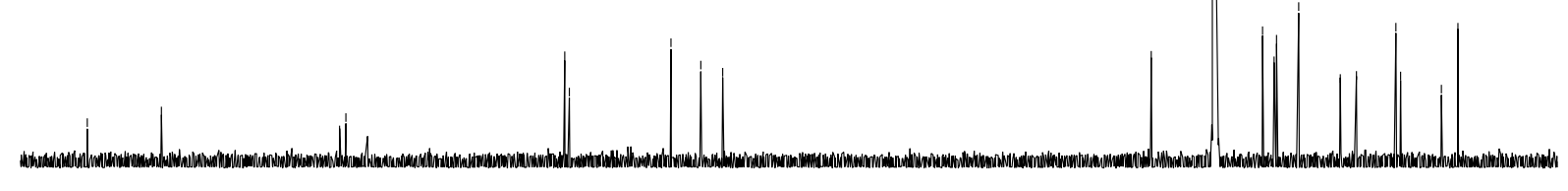

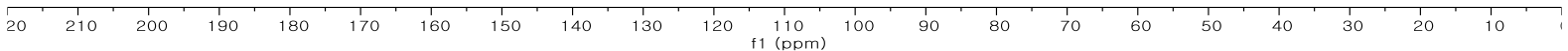


Figure S13. COSY spectrum of formicin $\mathrm{B}(2)$ at $800 \mathrm{MHz}$ in $\mathrm{CD}_{3} \mathrm{OD}$.

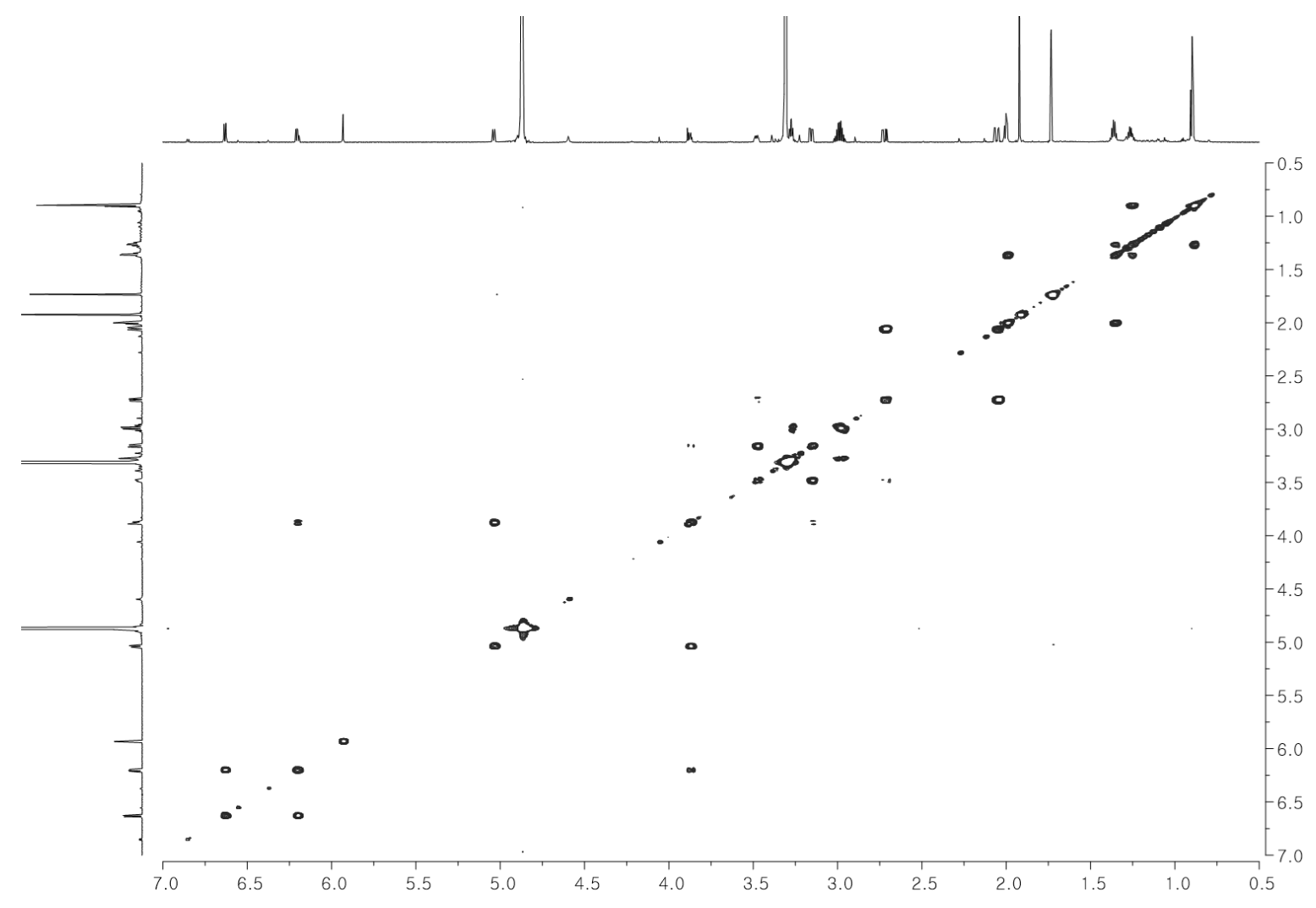

Figure S14. HSQC spectrum of formicin B (2) at $800 \mathrm{MHz}$ in $\mathrm{CD}_{3} \mathrm{OD}$.

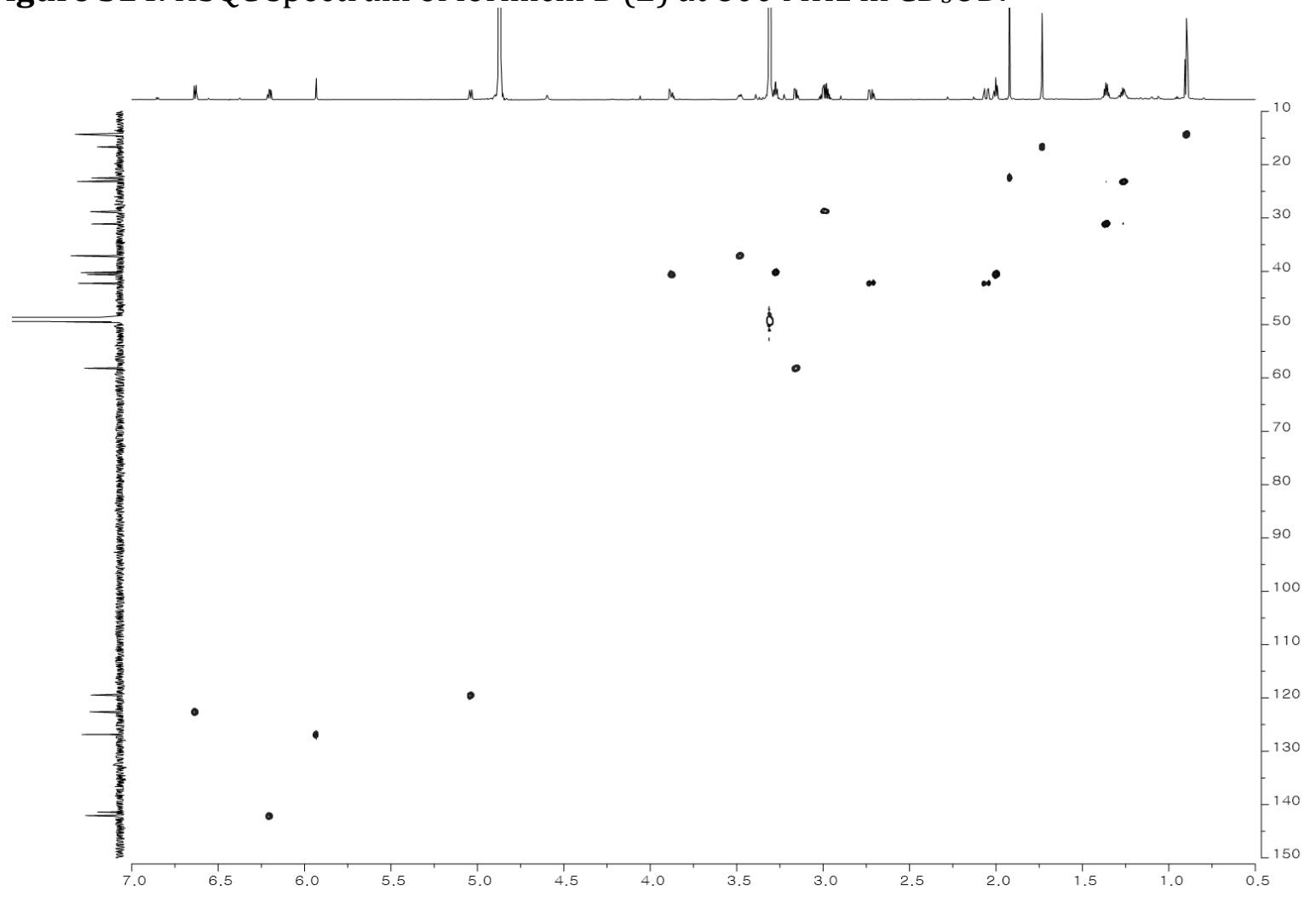


Figure S15. HMBC spectrum of formicin B (2) at $800 \mathrm{MHz}$ in $\mathrm{CD}_{3} \mathrm{OD}$.

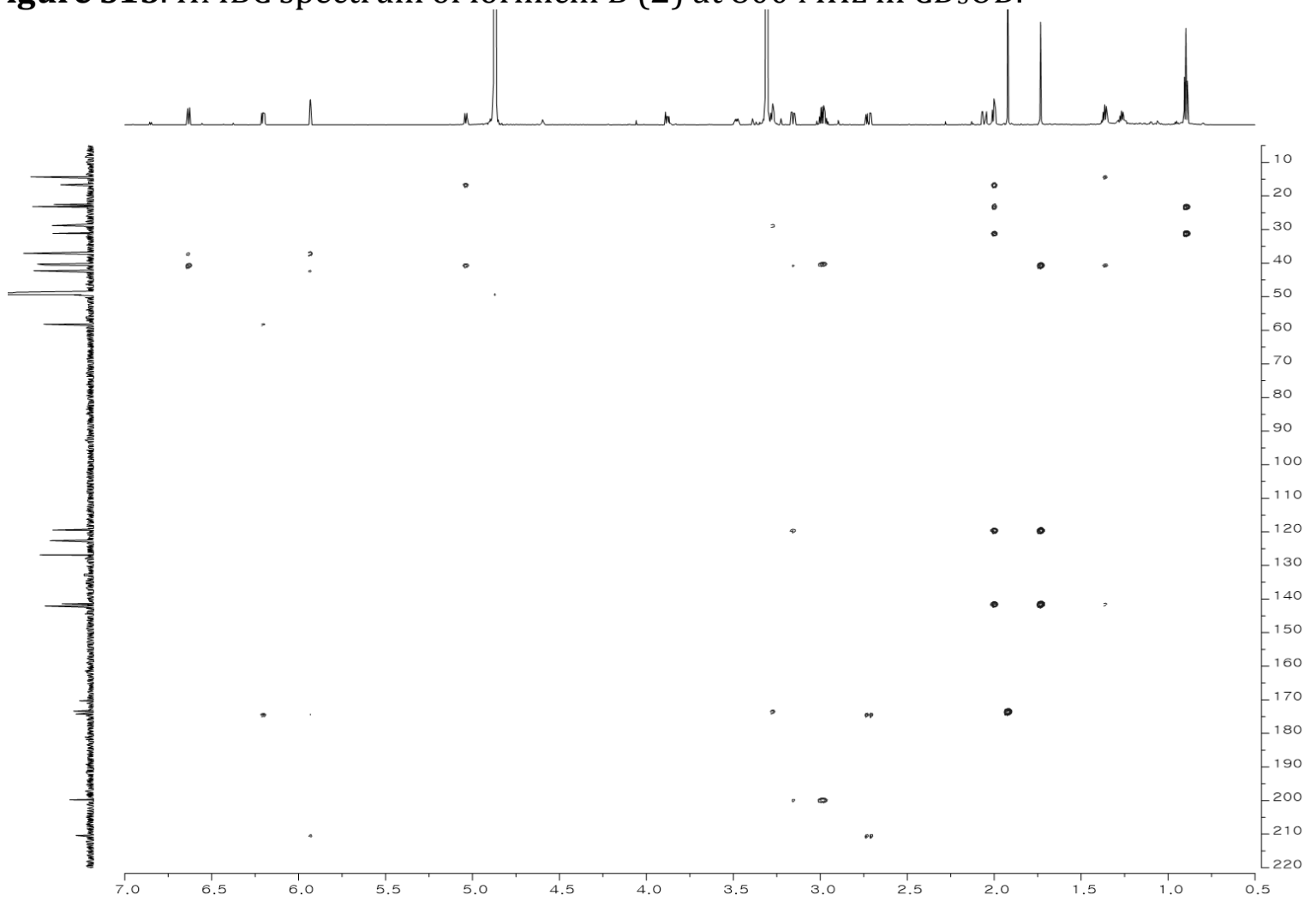

Figure S16. ROESY spectrum of formicin B (2) at $800 \mathrm{MHz}$ in $\mathrm{CD}_{3} \mathrm{OD}$.

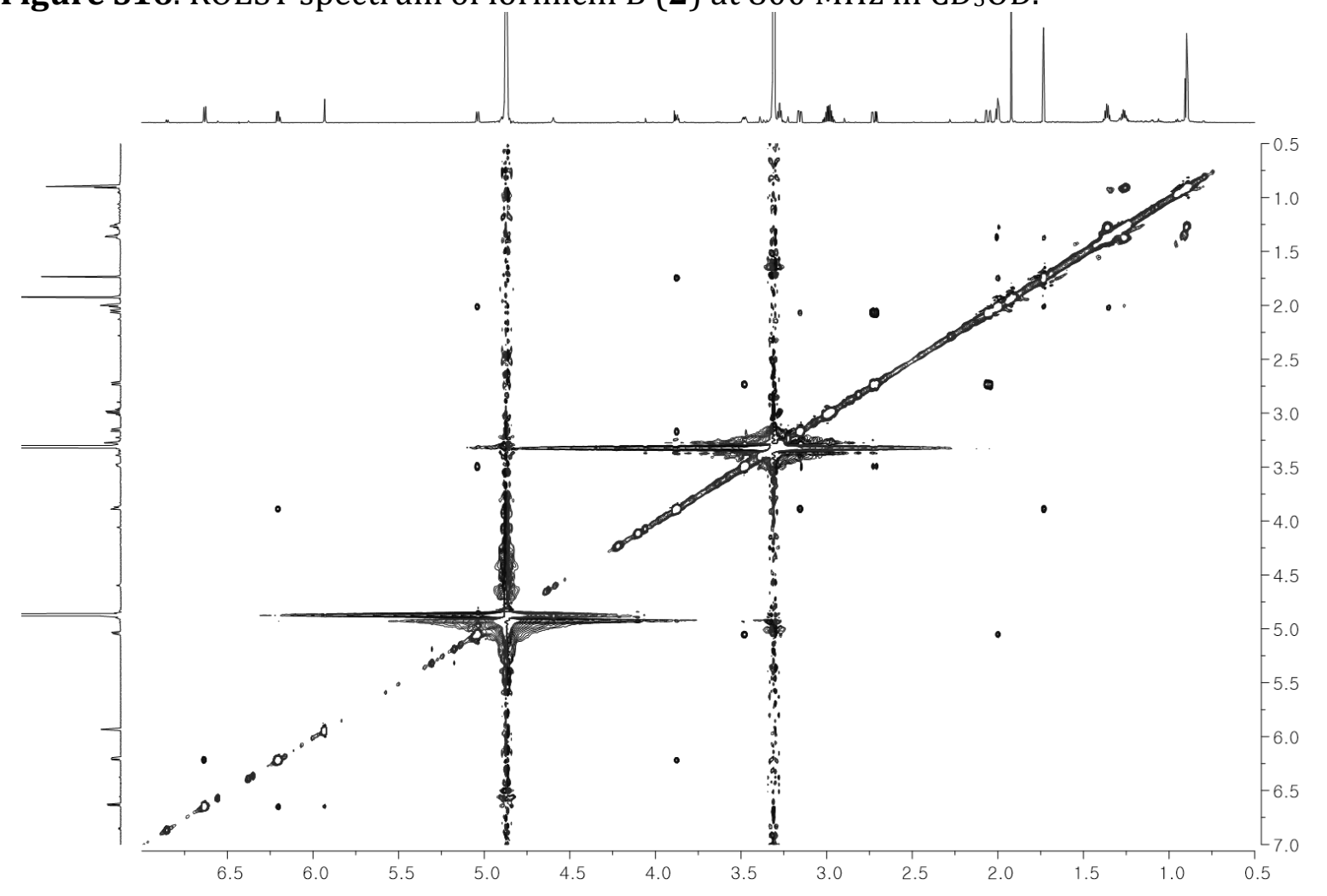


Figure S17. ${ }^{1} \mathrm{H}$ NMR spectrum of formicin C (3) at $800 \mathrm{MHz}$ in $\mathrm{CD}_{3} \mathrm{OD}$.

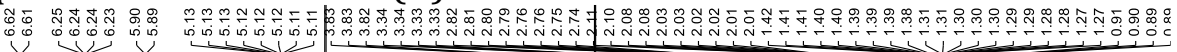<smiles>CCCC/C(C)=C/[C@H]1C=CC2=CC(=O)C[C@H]2[C@H]1C(=O)O</smiles>

3

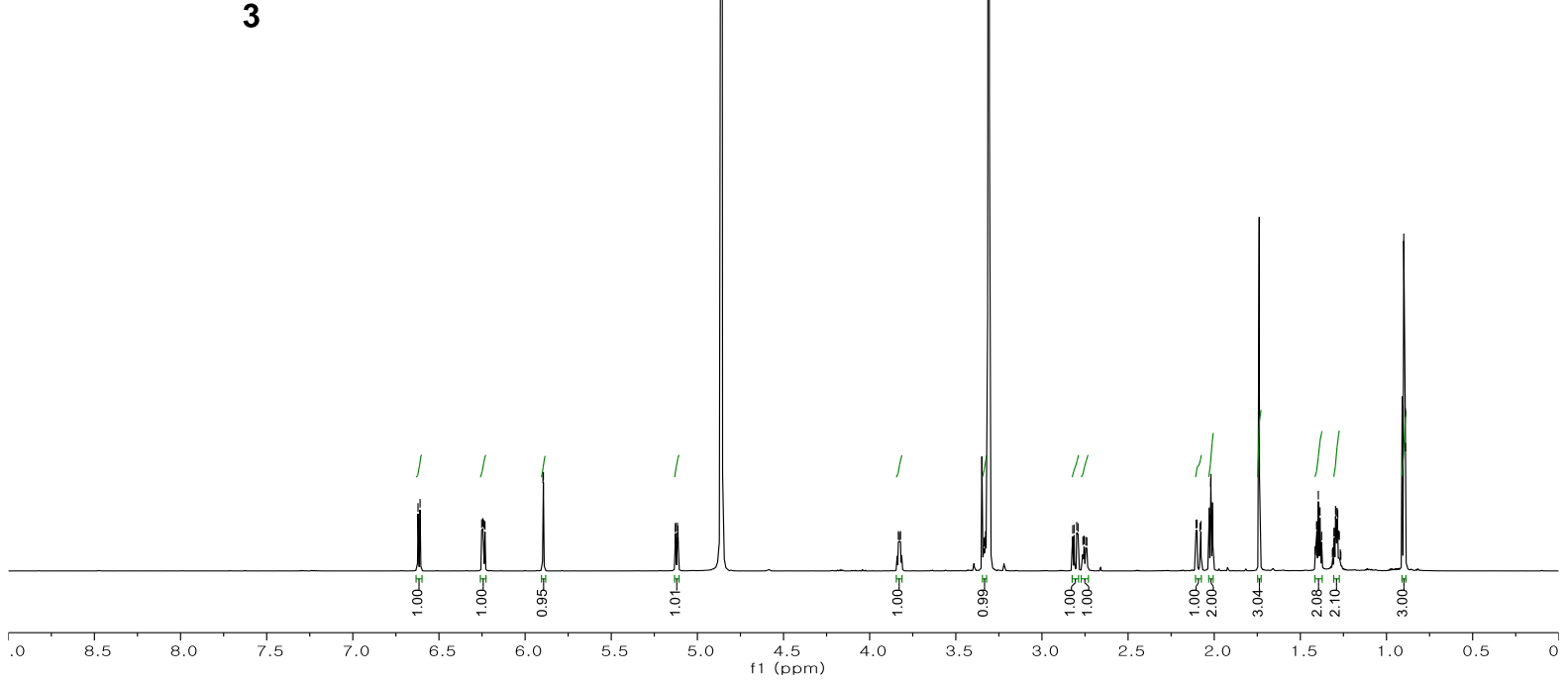

Figure S18. ${ }^{13} \mathrm{C}$ NMR spectrum of formicin C (3) at $200 \mathrm{MHz}$ in $\mathrm{CD}_{3} \mathrm{OD}$.

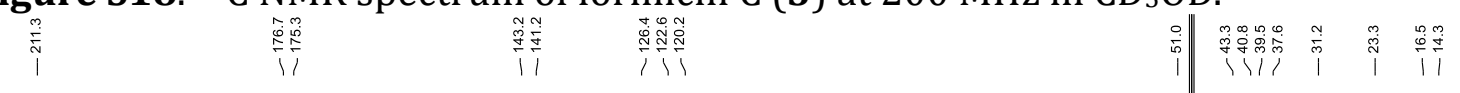<smiles>CCCC/C(C)=C/[C@H]1C=CC2=CC(=O)C[C@H]2[C@H]1C(=O)O</smiles>

3

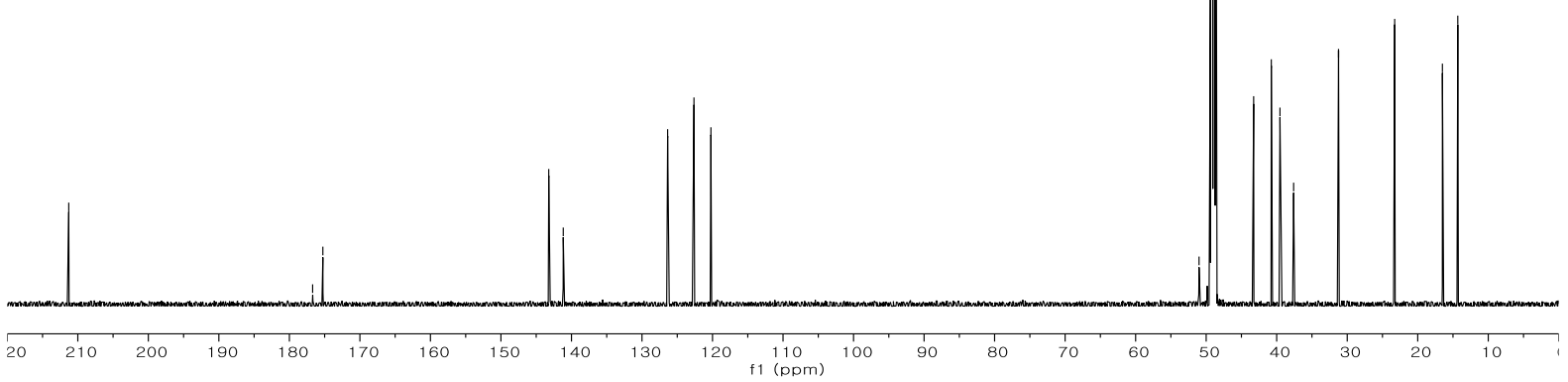


Figure S19. COSY spectrum of formicin C (3) at $800 \mathrm{MHz}$ in $\mathrm{CD}_{3} \mathrm{OD}$.

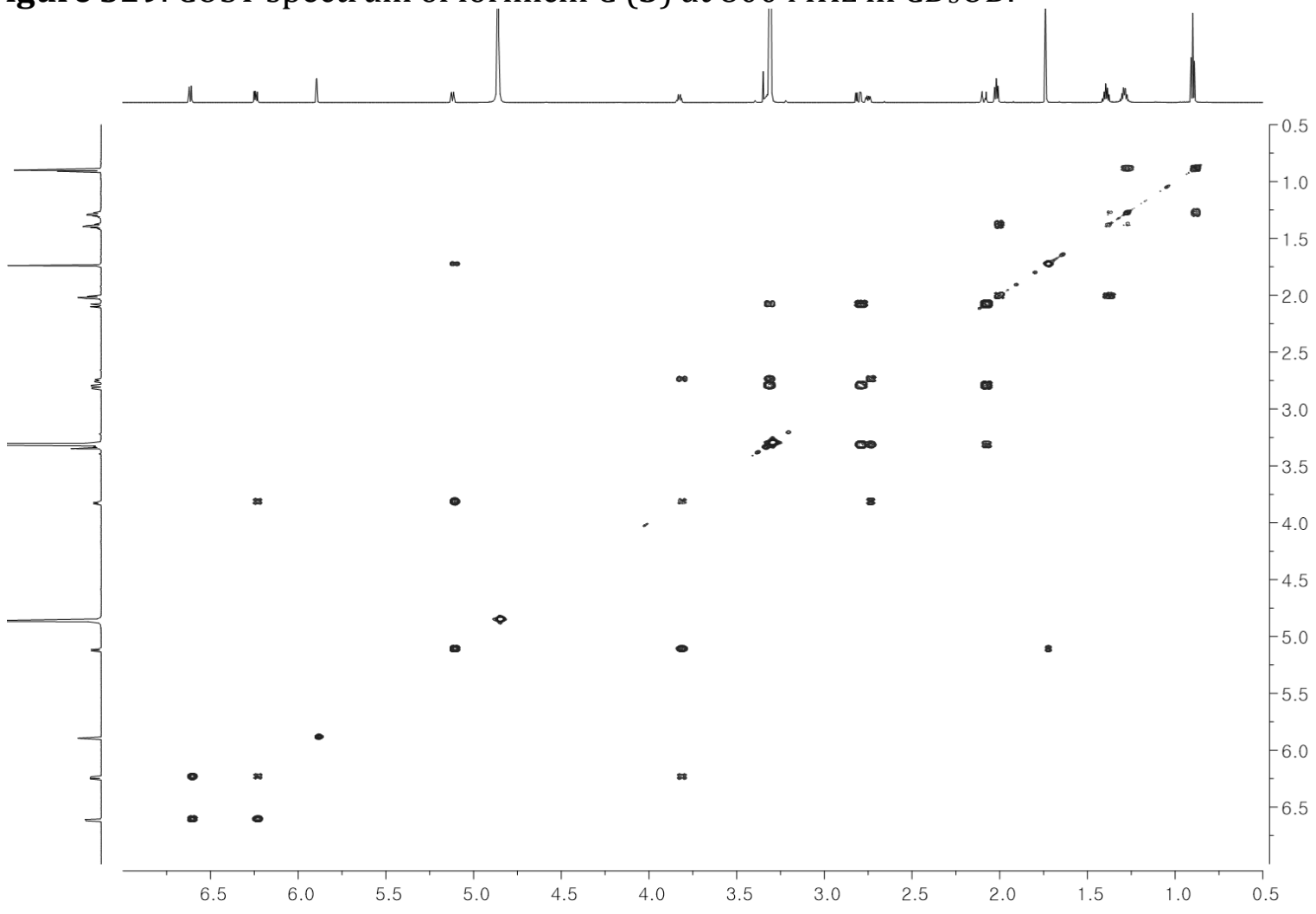

Figure S20. HSQC spectrum of formicin C (3) at $800 \mathrm{MHz}$ in $\mathrm{CD}_{3} \mathrm{OD}$.

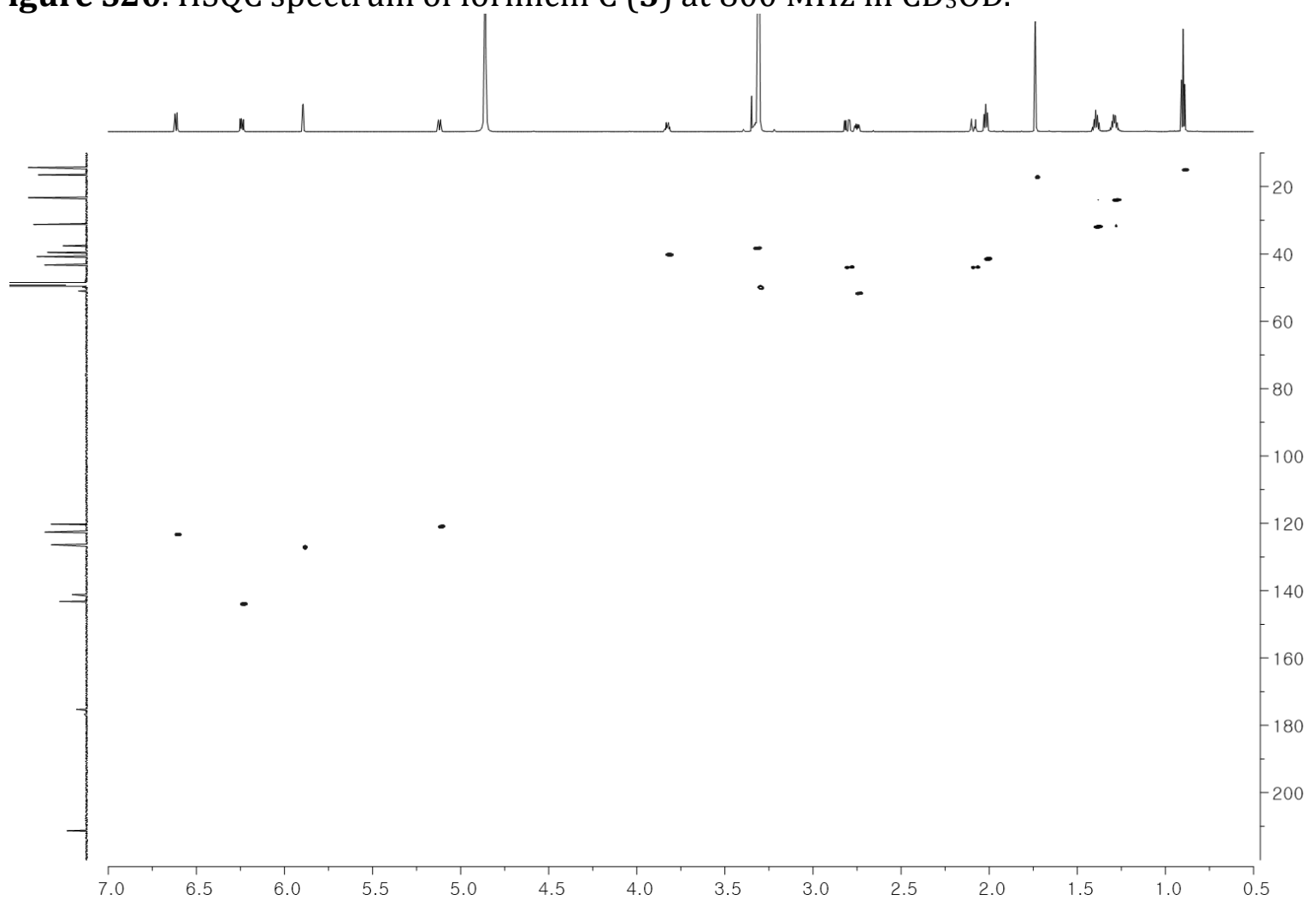


Figure S21. $\mathrm{HMBC}$ spectrum of formicin C (3) at $800 \mathrm{MHz}$ in $\mathrm{CD}_{3} \mathrm{OD}$.

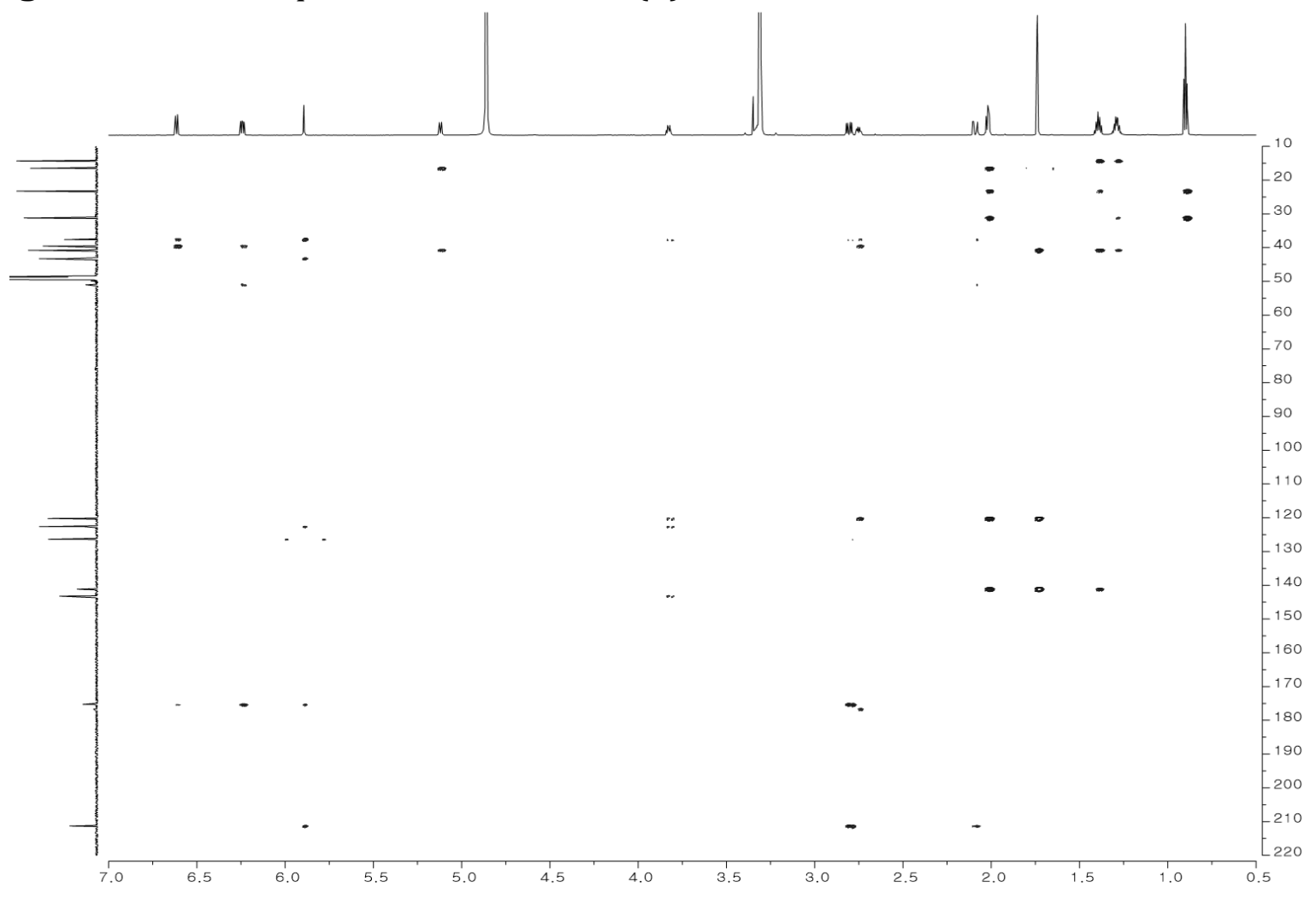

Figure S22. ROESY spectrum of formicin C (3) at $800 \mathrm{MHz}$ in $\mathrm{CD}_{3} \mathrm{OD}$.

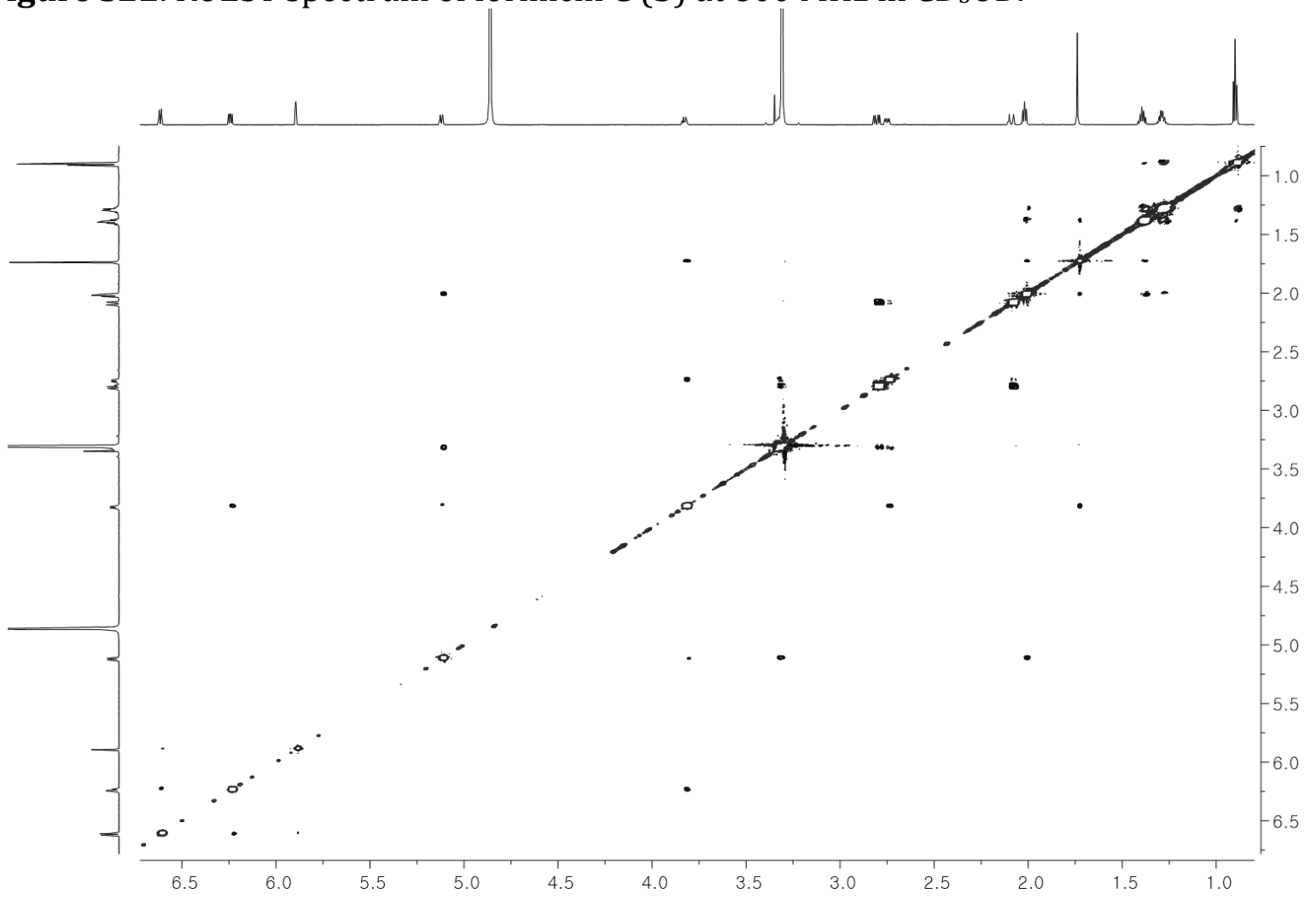


Figure S23. ${ }^{1} \mathrm{H}$ NMR spectrum of $S$-PGME amide (3a) of formicin C (3) at $800 \mathrm{MHz}$ in $\mathrm{CD}_{3} \mathrm{OD}$.

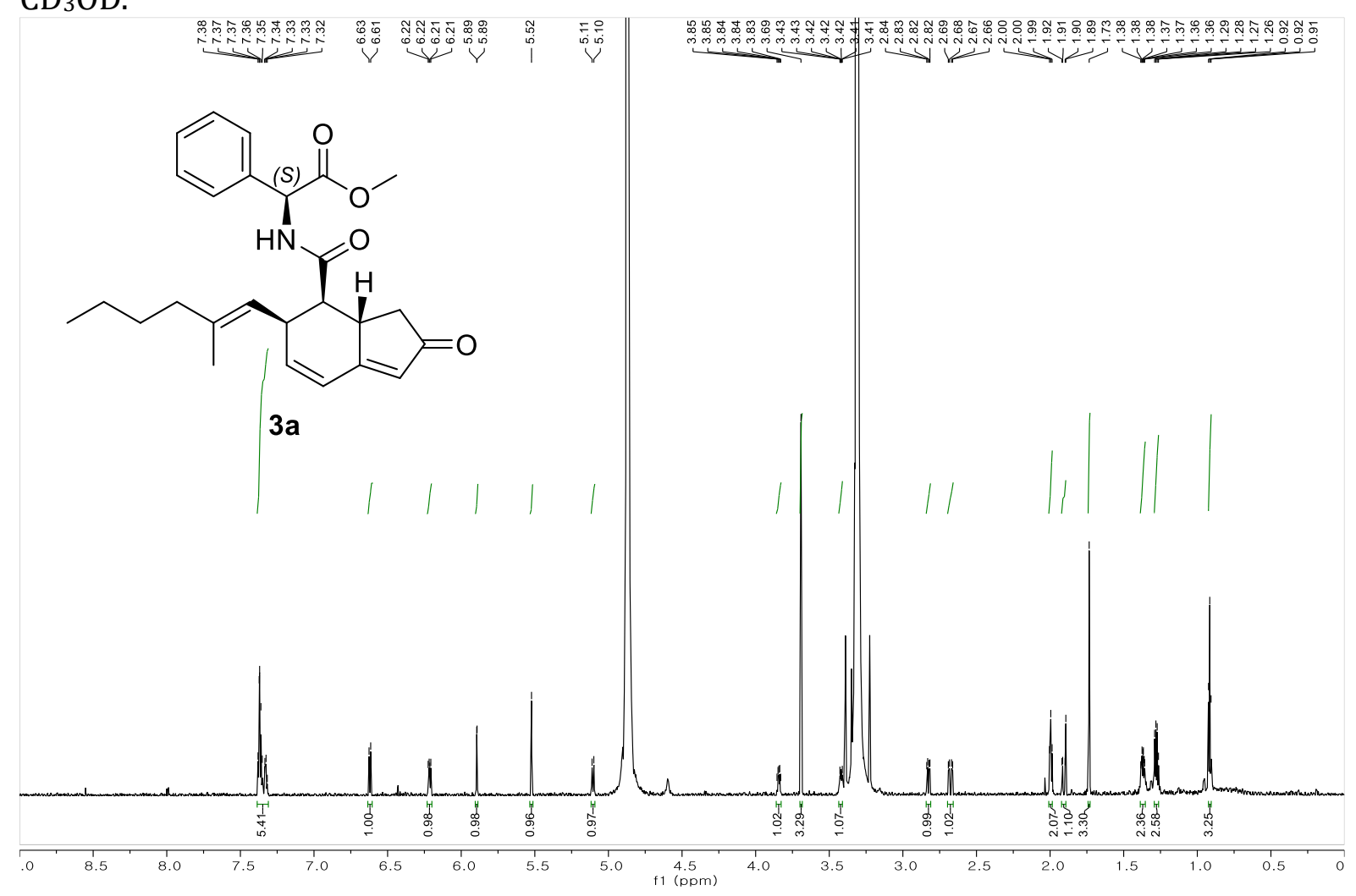

Figure S24. COSY spectrum of $S$-PGME amide (3a) of formicin C (3) at $800 \mathrm{MHz}$ in $\mathrm{CD}_{3} \mathrm{OD}$.

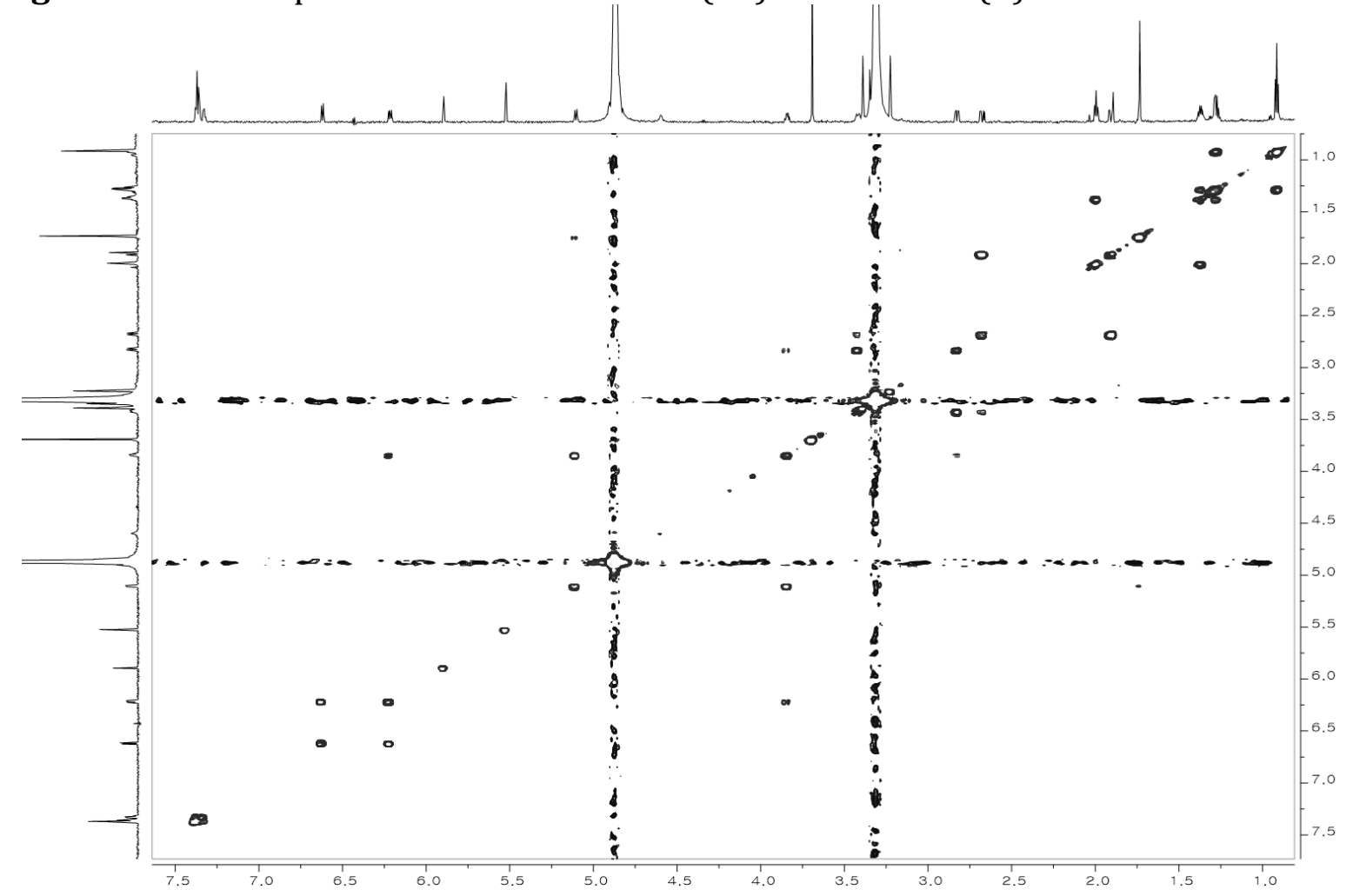


Figure S25. ${ }^{1} \mathrm{H}$ NMR spectrum of $R$-PGME amide (3b) of formicin C (3) at $800 \mathrm{MHz}$ in $\mathrm{CD}_{3} \mathrm{OD}$.

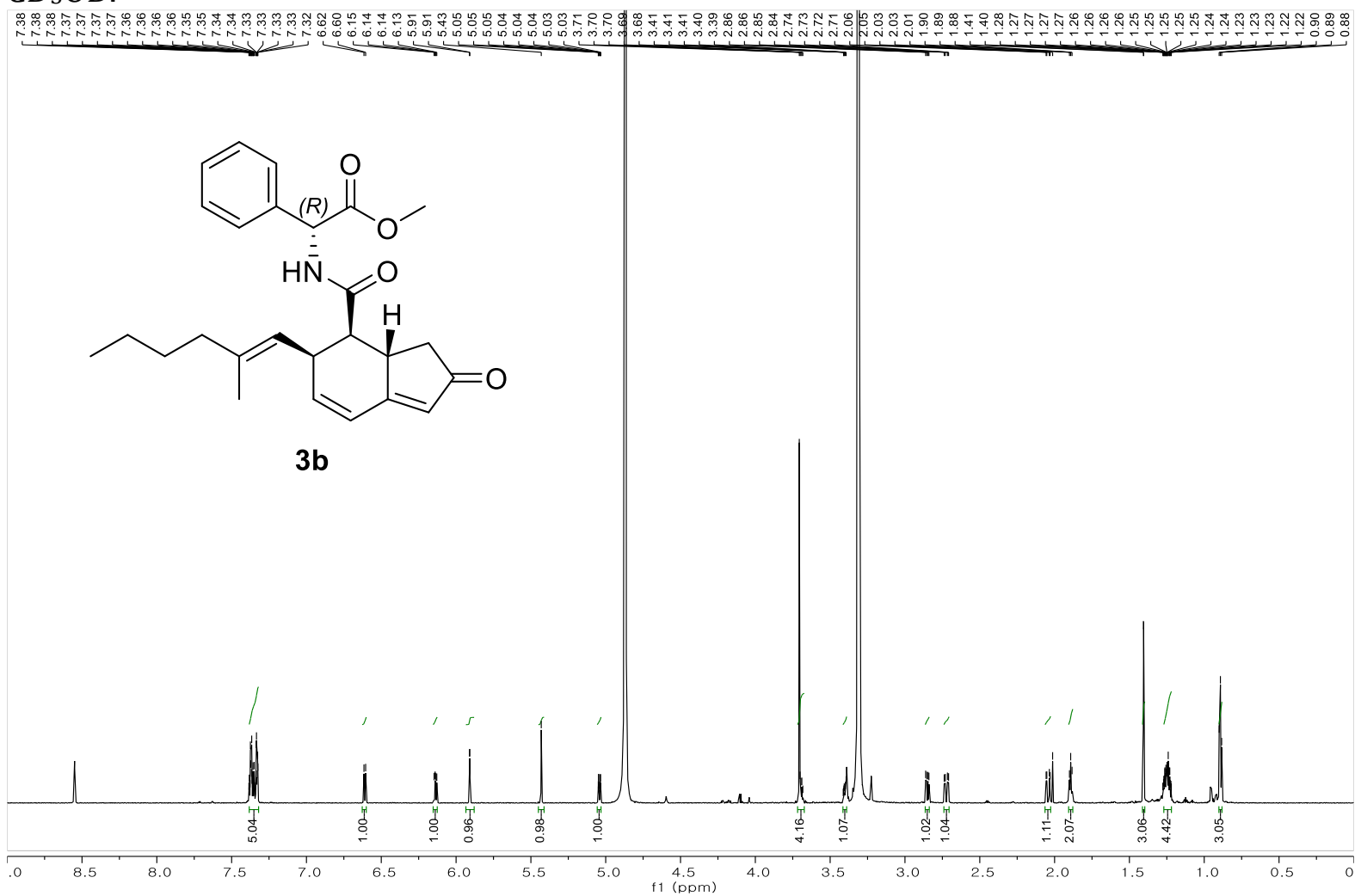

Figure S26. COSY spectrum of $R$-PGME amide (3b) of formicin C (3) at $800 \mathrm{MHz}$ in $\mathrm{CD}_{3} \mathrm{OD}$.

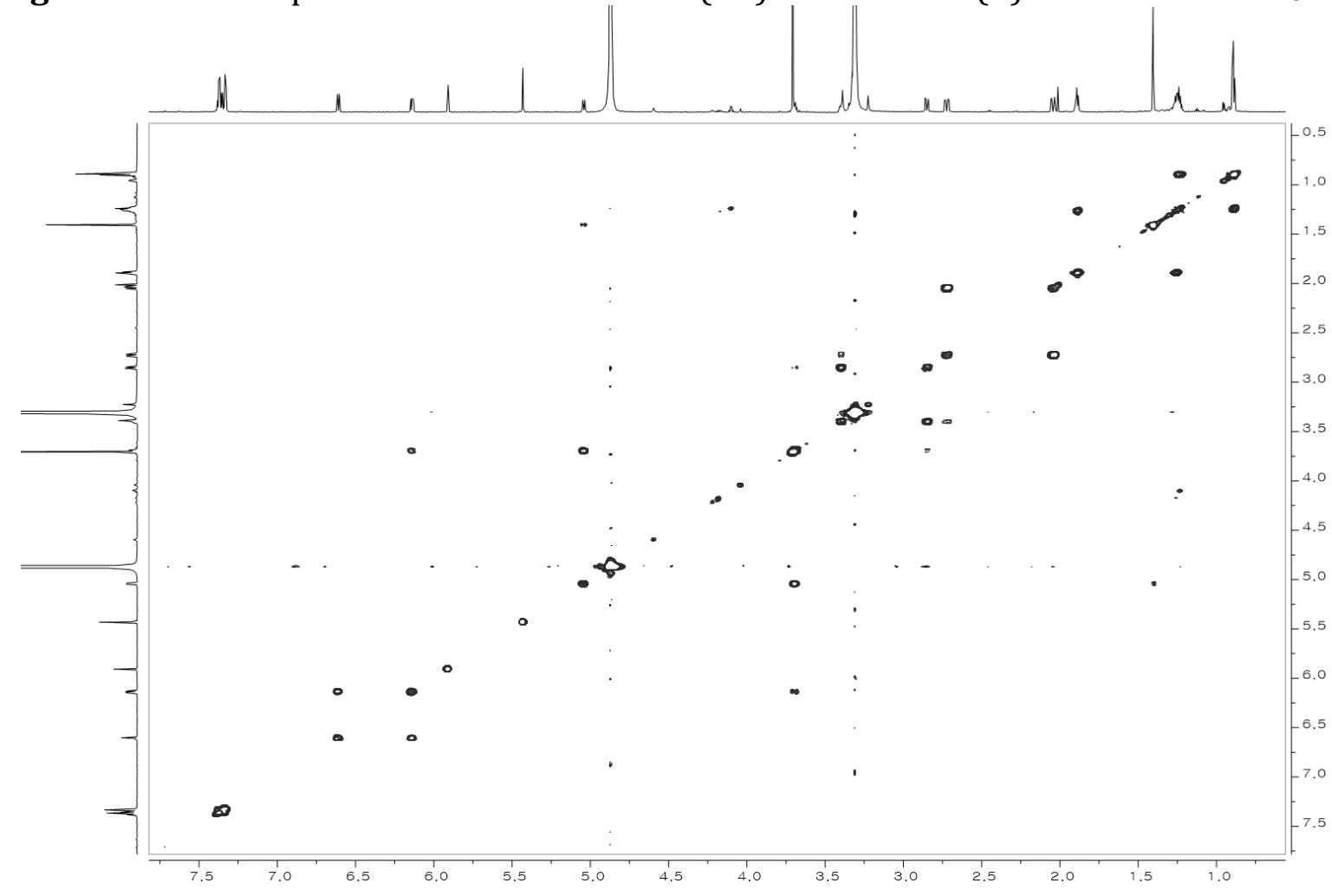


Figure S27. Key ROESY correlations of formicin C (3).

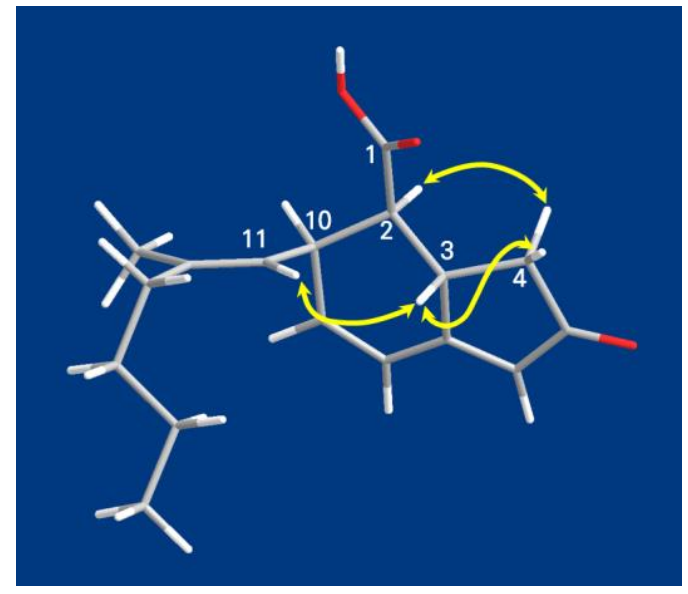

Figure S28. $\Delta \delta_{S-R}$ values (ppm) of PGME products (3a and $\mathbf{3 b}$ ).

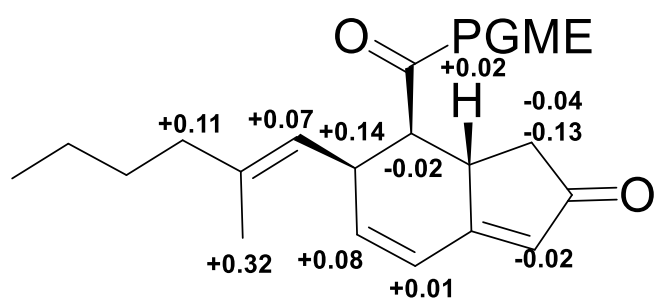


Figure S29. ${ }^{1} \mathrm{H}$ NMR spectrum of $N$-acetylcysteamine at $400 \mathrm{MHz}$ in $\mathrm{CDCl}_{3}$.<smiles>CC(=O)NCCS</smiles>

$\mathrm{N}$-acetylcysteamine

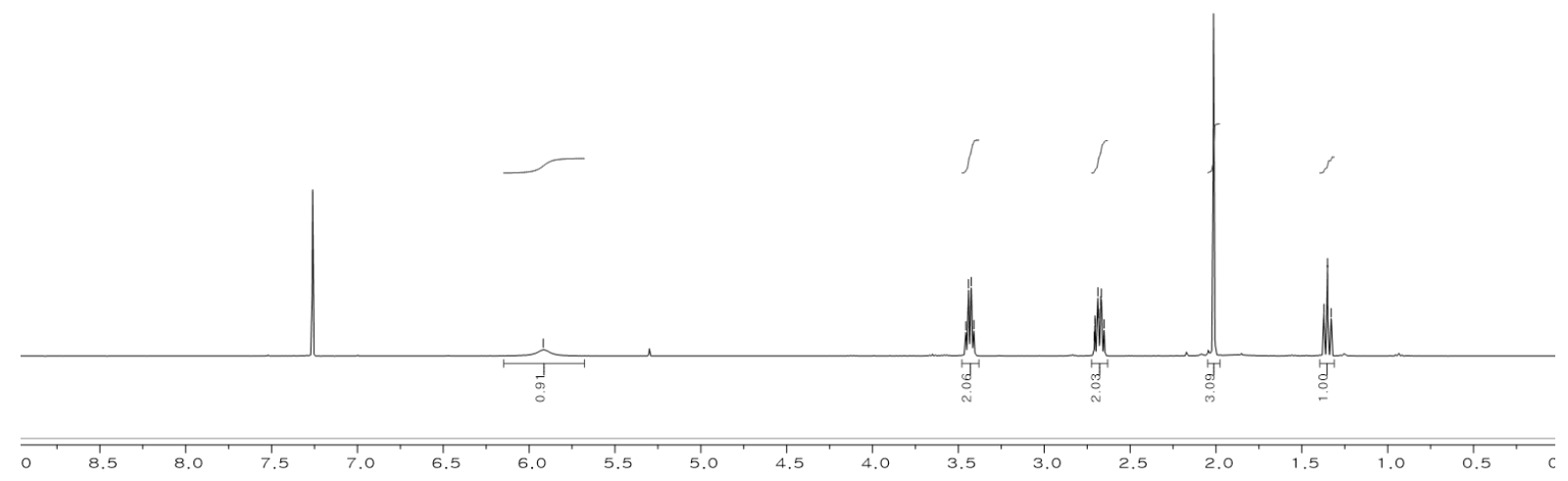

Figure S30. ${ }^{13} \mathrm{C}$ NMR spectrum of $N$-acetylcysteamine at $100 \mathrm{MHz}$ in $\mathrm{CDCl}_{3}$.

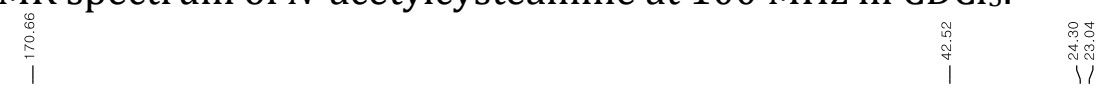<smiles>CC(=O)NCCS</smiles>

$N$-acetylcysteamine

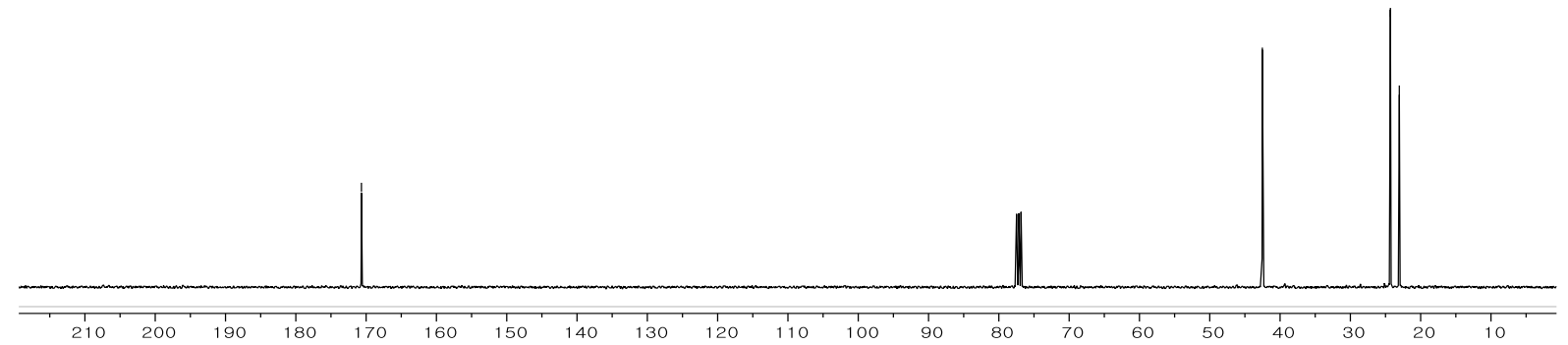


Figure S31. ${ }^{1} \mathrm{H}$ NMR spectrum of synthetic formicin B (2a) at $800 \mathrm{MHz}$ in $\mathrm{CD}_{3} \mathrm{OD}$.

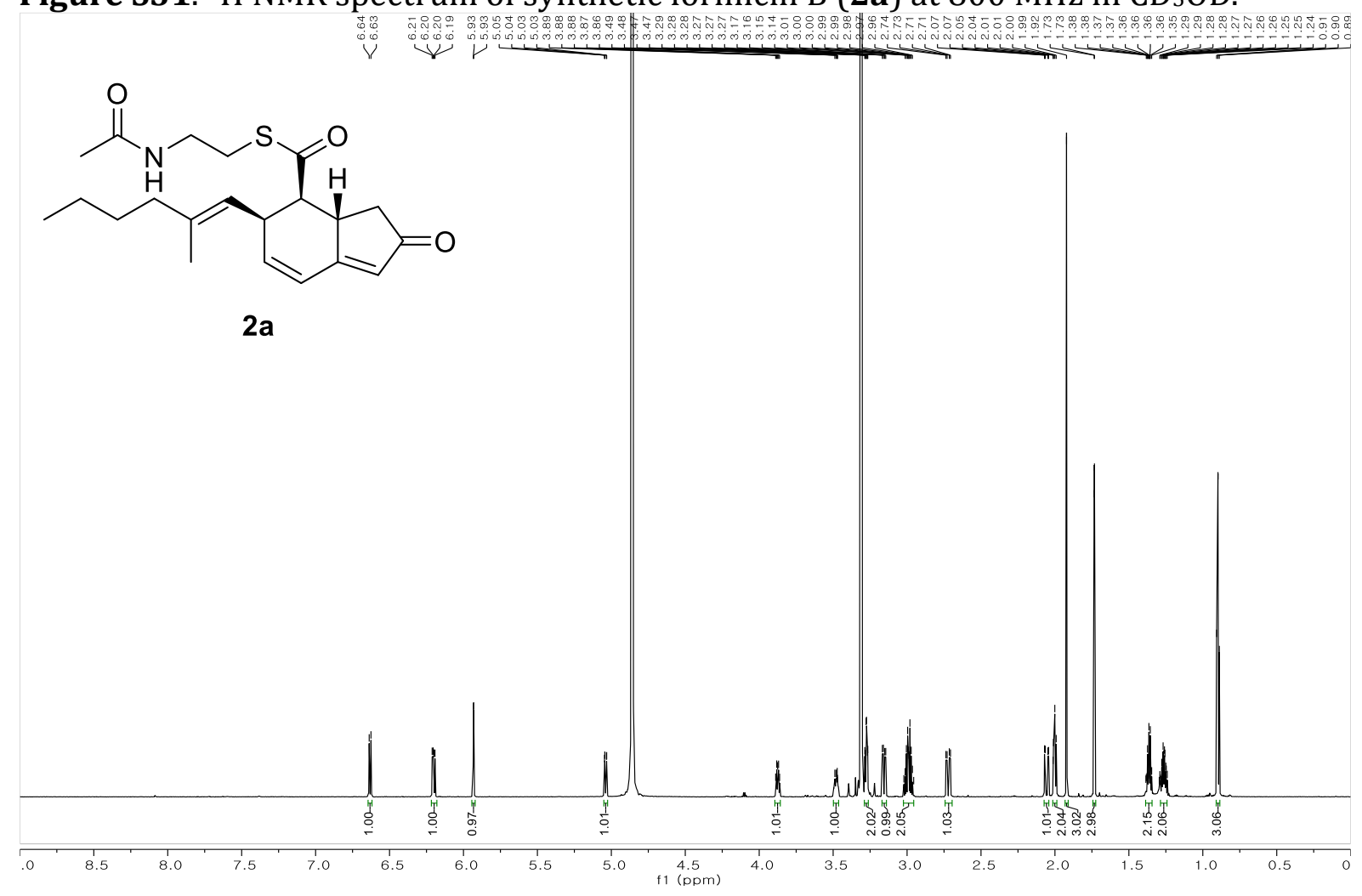

Figure S32. ${ }^{13} \mathrm{C}$ NMR spectrum of synthetic formicin B (2a) at $200 \mathrm{MHz}$ in $\mathrm{CD}_{3} \mathrm{OD}$.

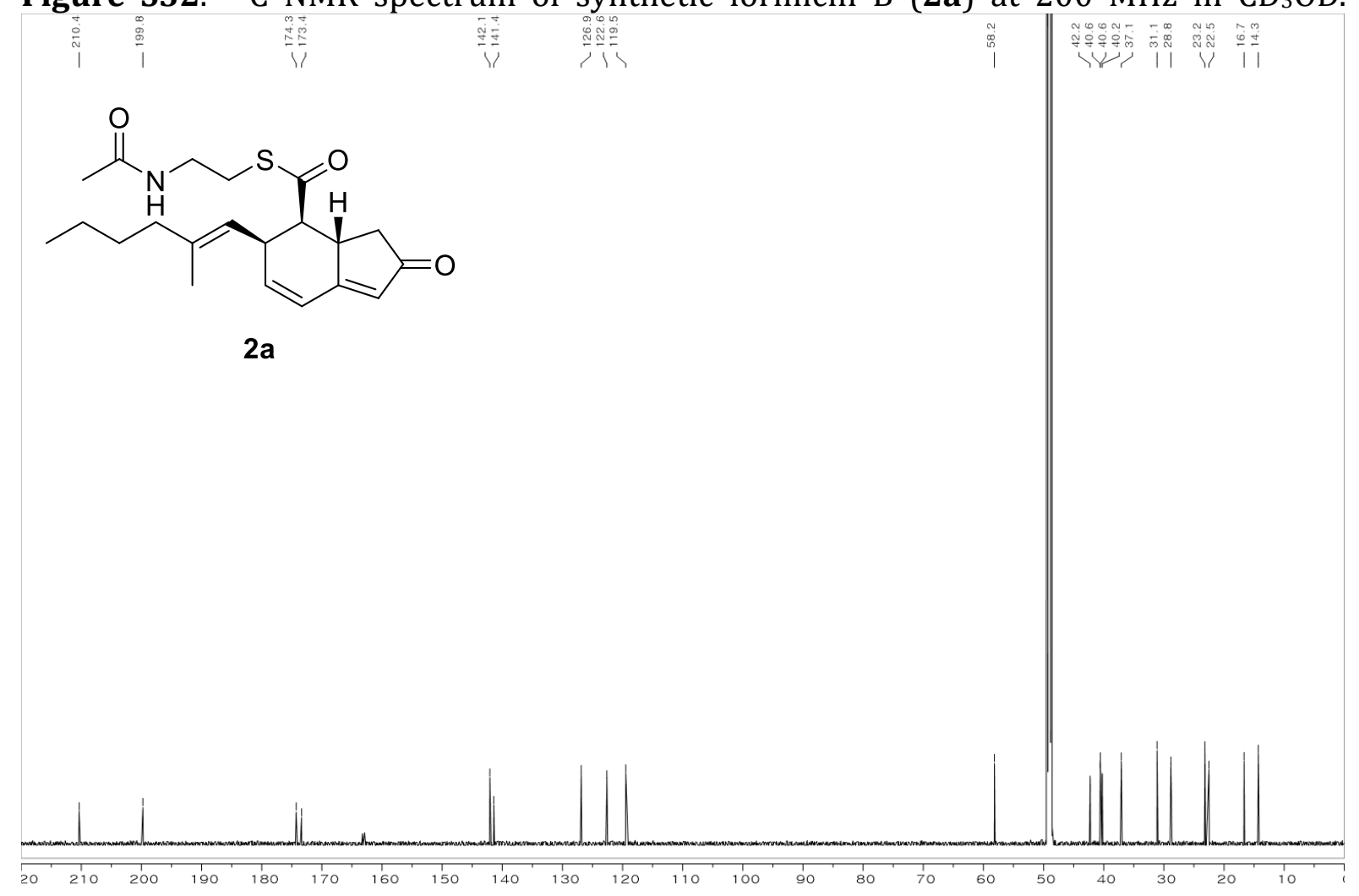


Figure S33. COSY spectrum of synthetic formicin B (2a) at $800 \mathrm{MHz}$ in $\mathrm{CD}_{3} \mathrm{OD}$.

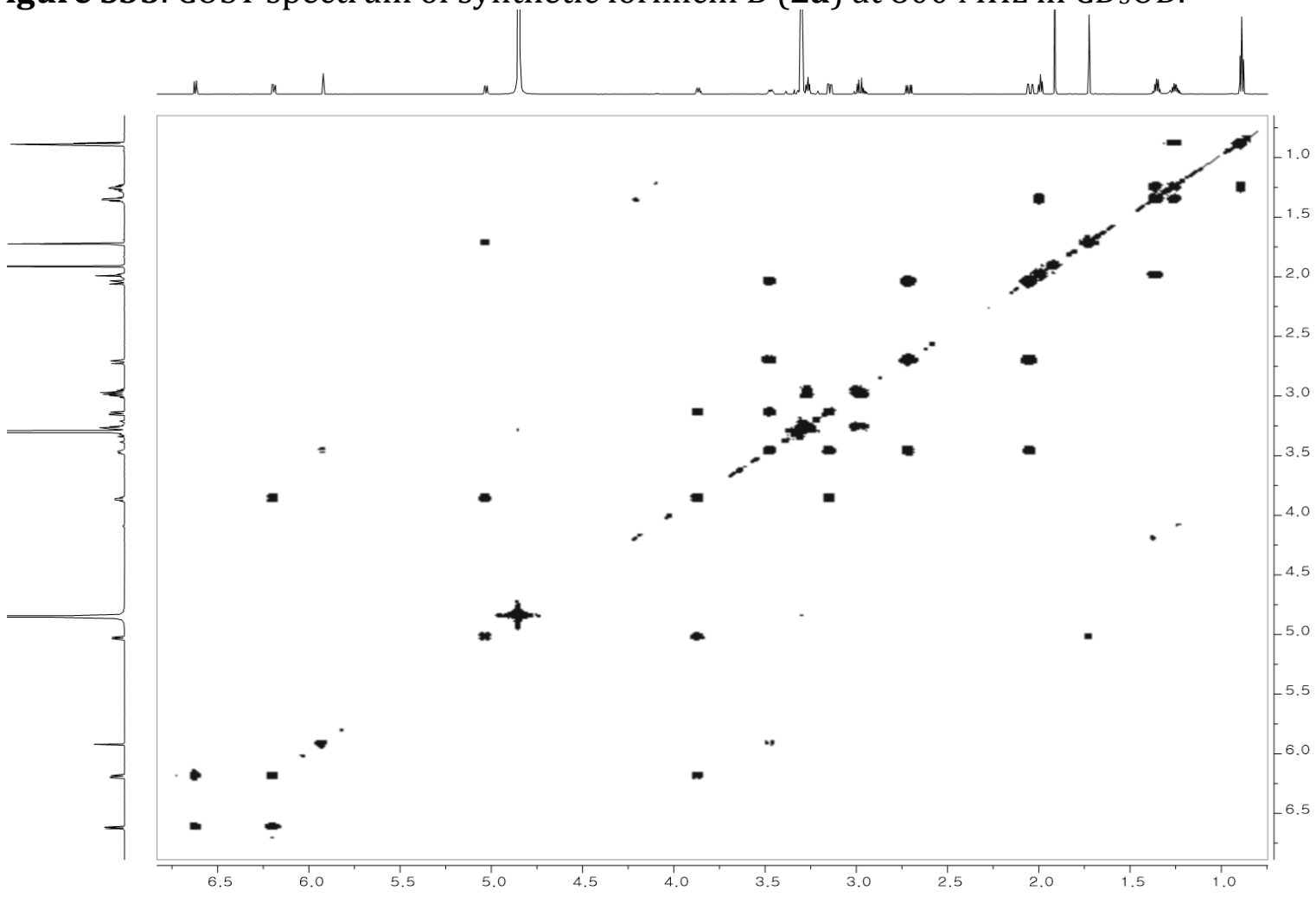

Figure S34. HSQC spectrum of synthetic formicin B (2a) at $800 \mathrm{MHz}$ in $\mathrm{CD}_{3} \mathrm{OD}$.

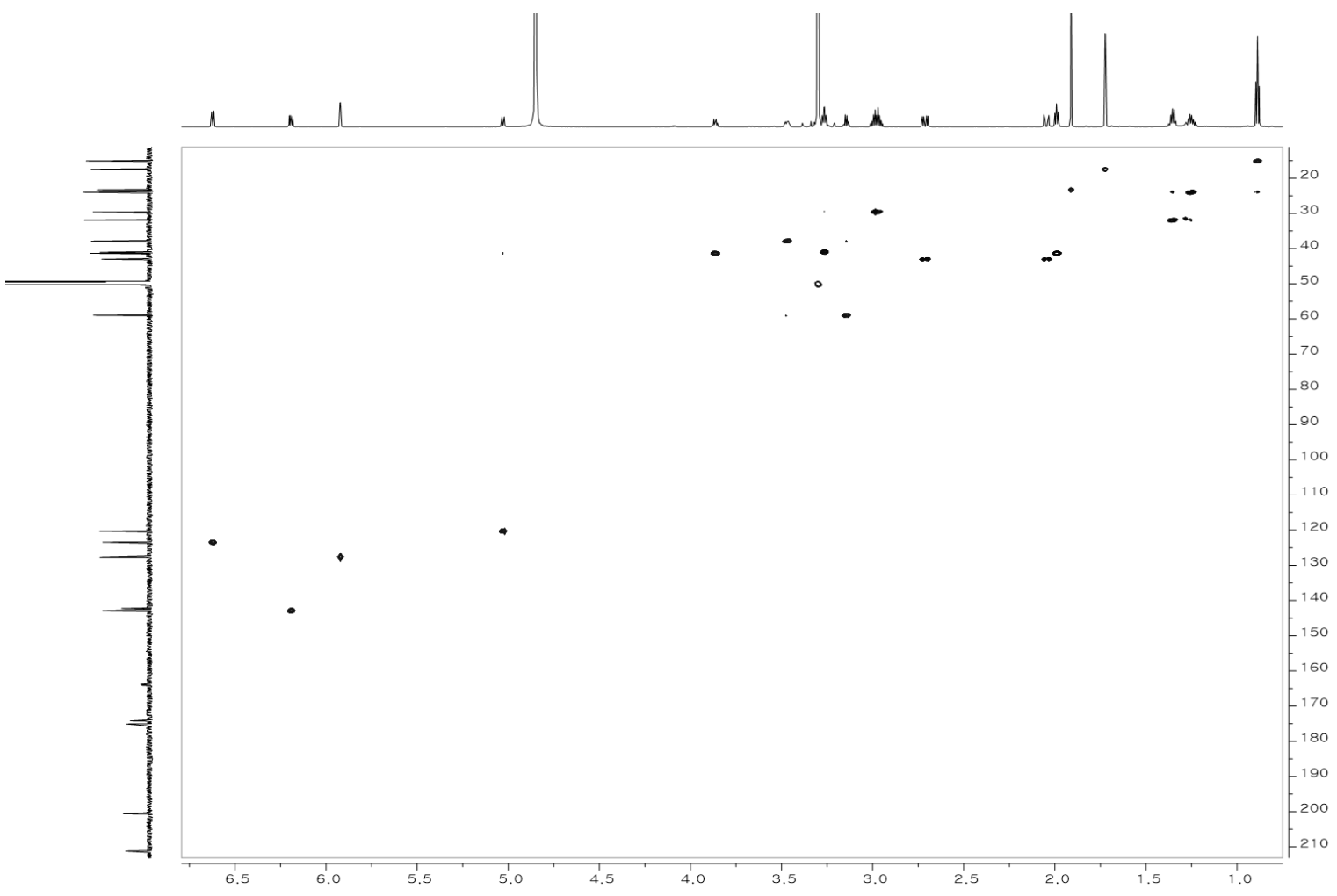


Figure S35. HMBC spectrum of synthetic formicin B (2a) at $800 \mathrm{MHz}$ in $\mathrm{CD}_{3} \mathrm{OD}$.

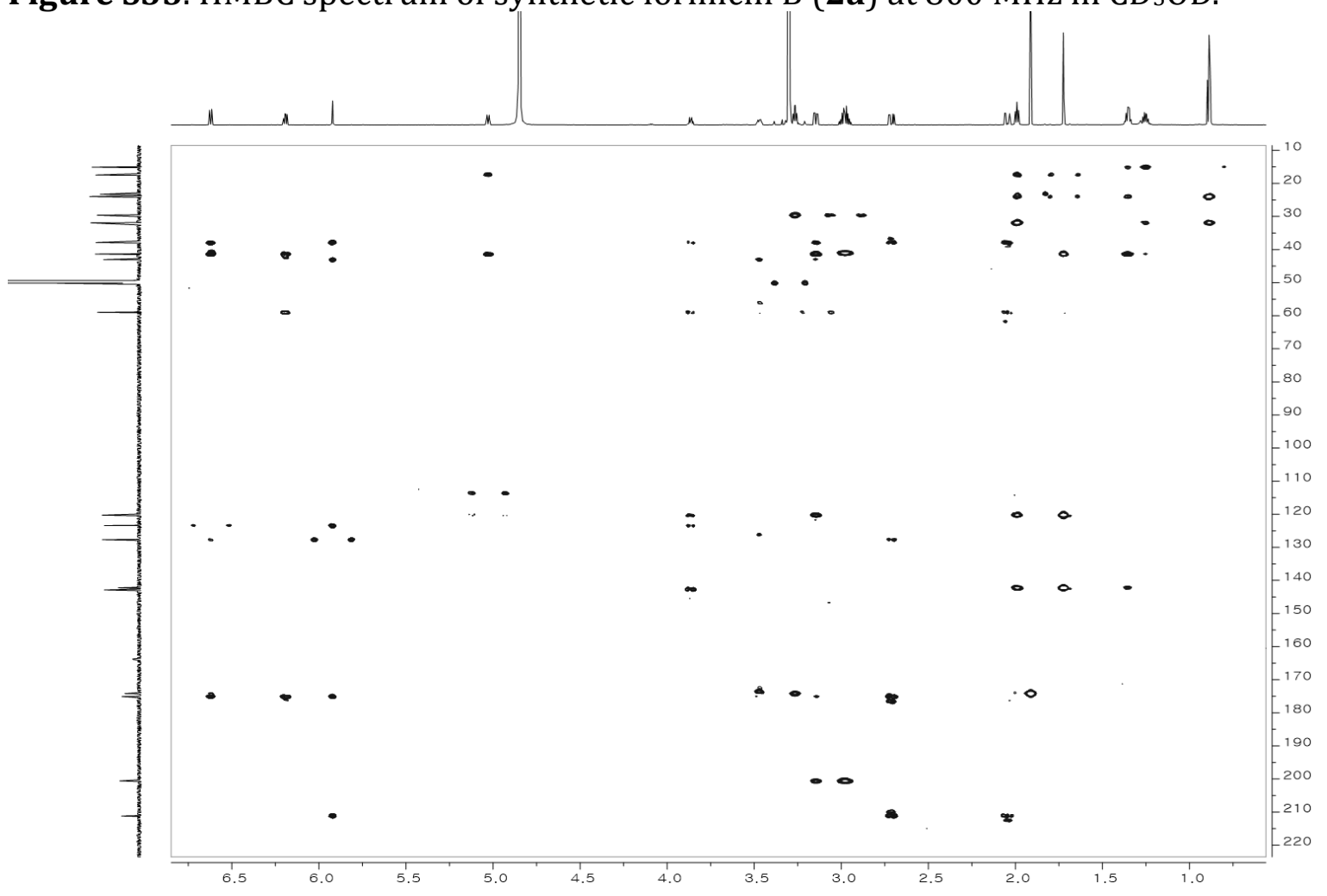

Figure S36. ROESY spectrum of synthetic formicin B (2a) at $800 \mathrm{MHz}$ in $\mathrm{CD}_{3} \mathrm{OD}$.

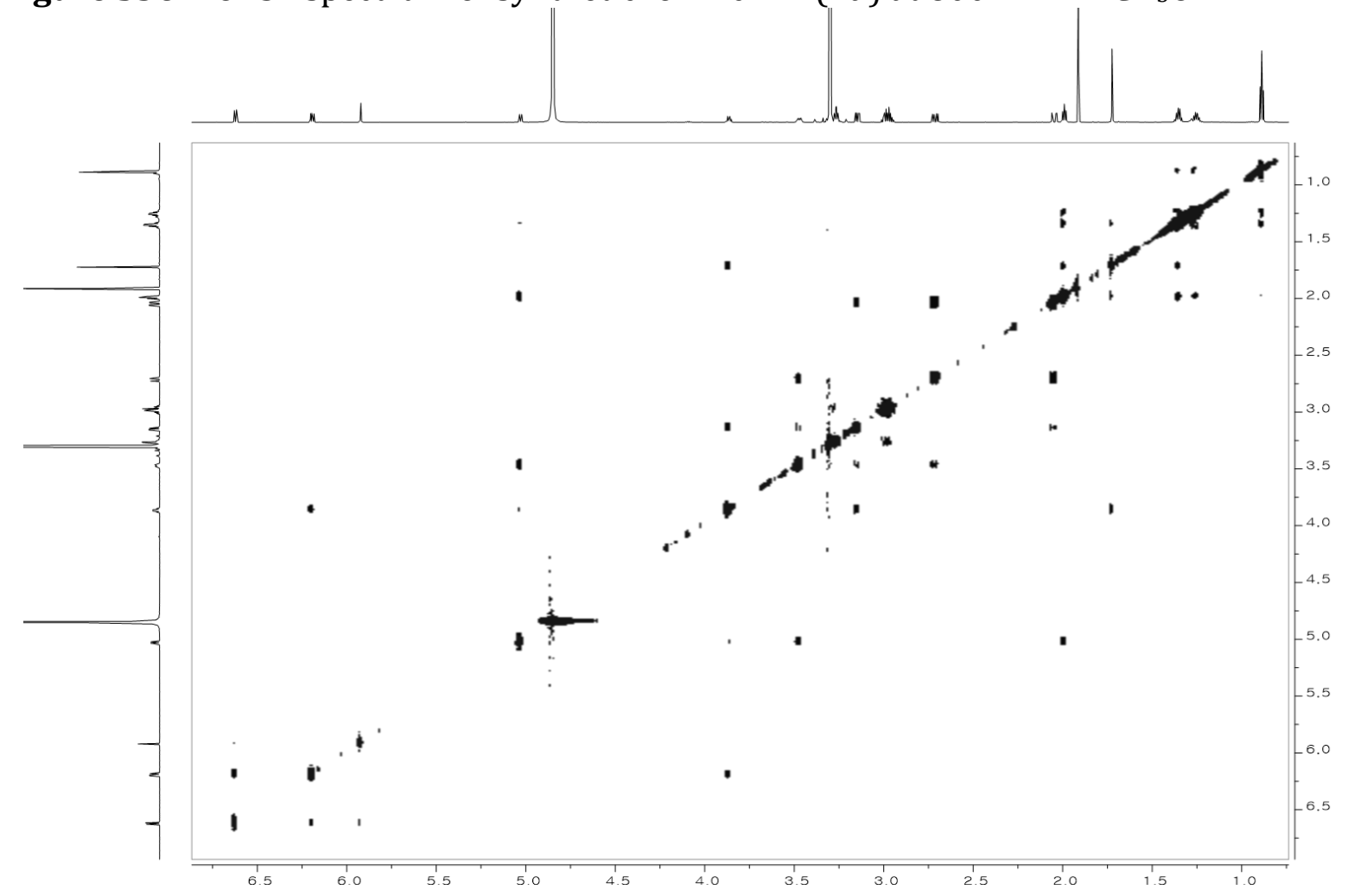


Figure S37. Comparison of ${ }^{1} \mathrm{H}$ NMR spectra of formicins A-B (1-2) and synthetic formicin $\mathrm{B}(\mathbf{2 a})$ at $800 \mathrm{MHz}$ in $\mathrm{CD}_{3} \mathrm{OD}$.

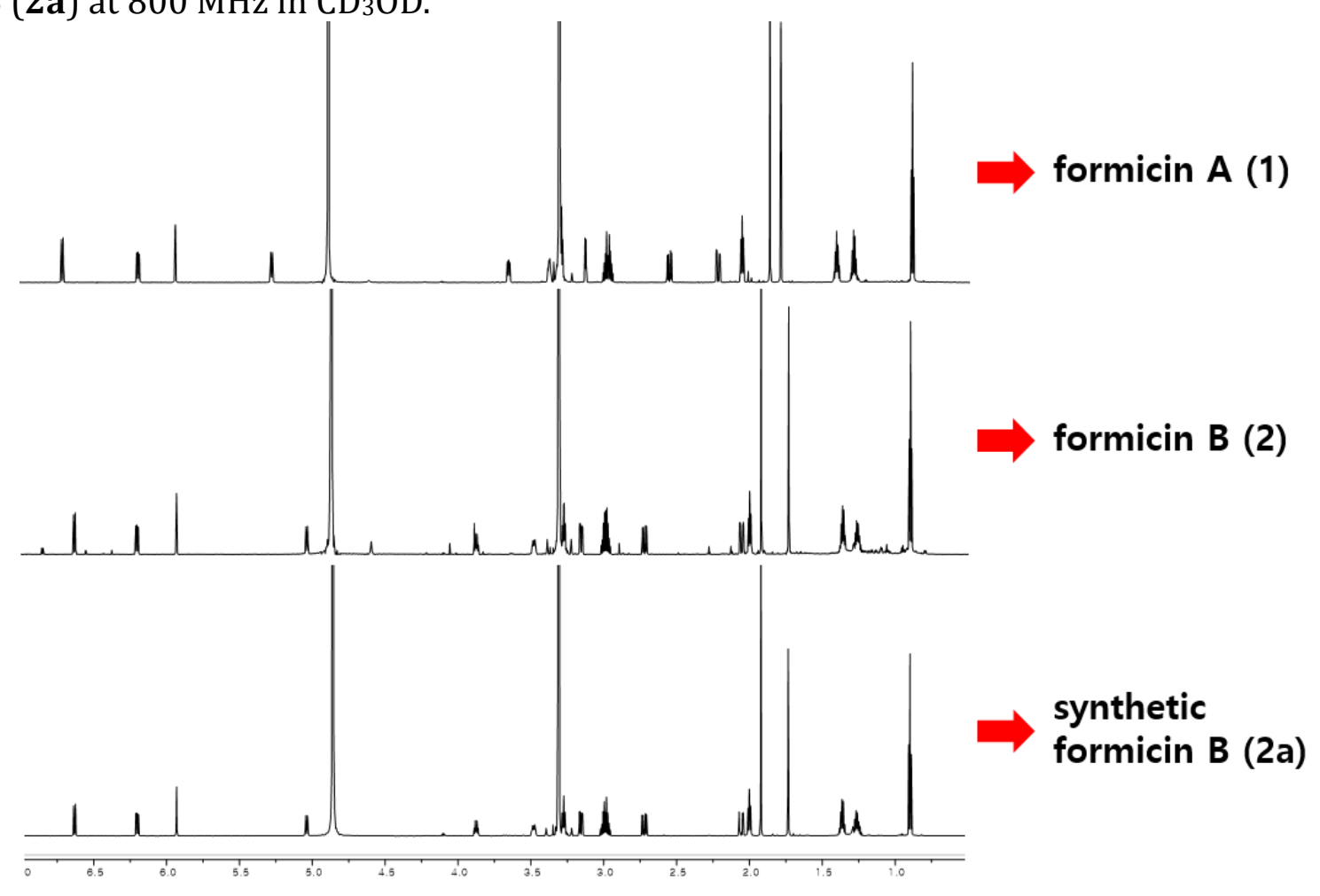

Figure S38. Comparison of ${ }^{13} \mathrm{C}$ NMR spectra of formicins A-B (1-2) and synthetic formicin $\mathrm{B}(\mathbf{2 a})$ at $200 \mathrm{MHz}$ in $\mathrm{CD}_{3} \mathrm{OD}$.

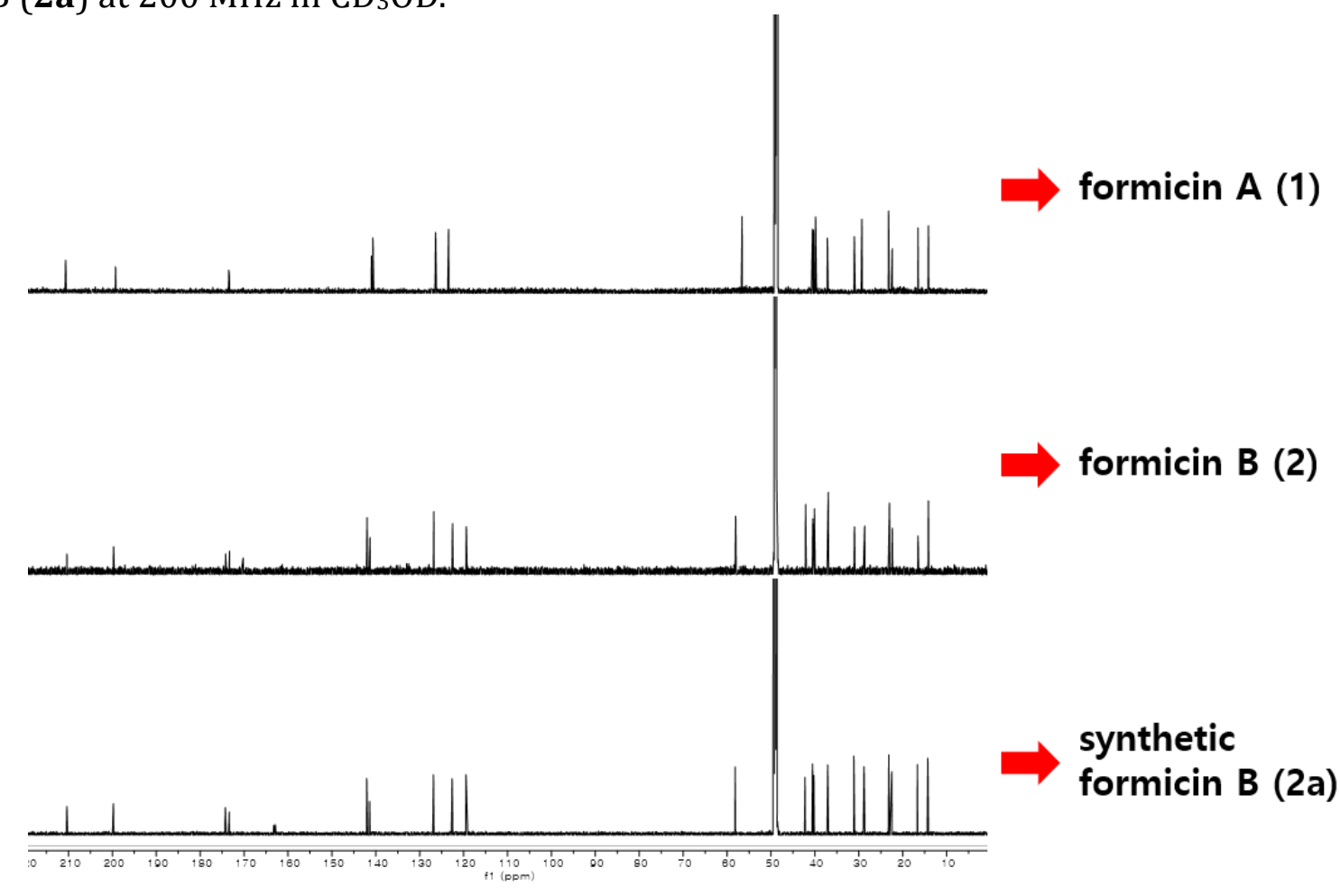


Figure S39. HPLC chromatograms of the isolated compounds $(\mathbf{1}, \mathbf{2}, \mathbf{2 a}, \mathbf{3}, \mathbf{3 a}$, and $\mathbf{3 b})$ (UV $280 \mathrm{~nm})$.

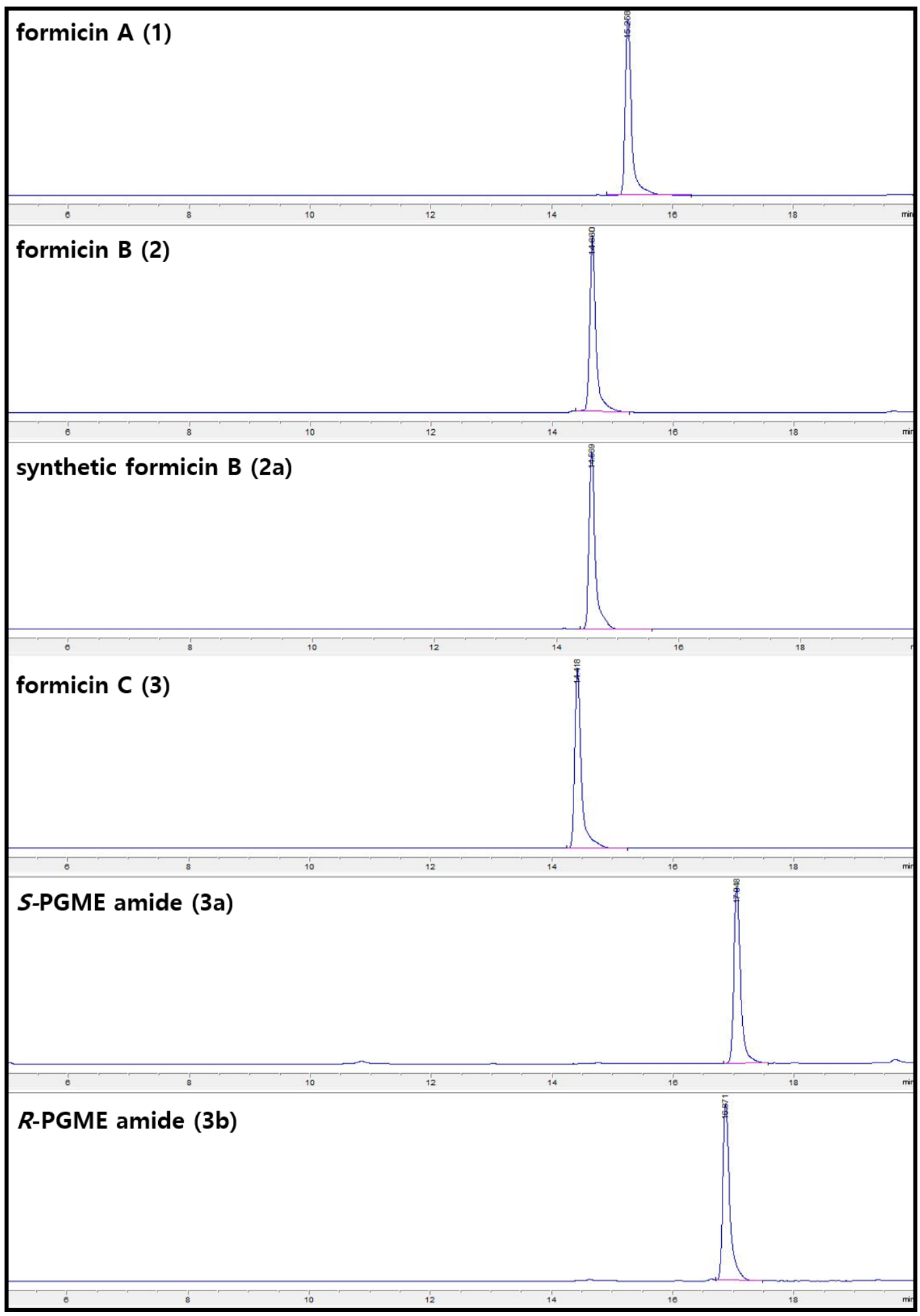


Figure S40. Effect of formicin A (1) on the cell proliferation of MRC-5 cells $(72 \mathrm{~h}$ incubation). Cell proliferation was measured using SRB assay. Data are expressed as means \pm SD from three independent experiments.

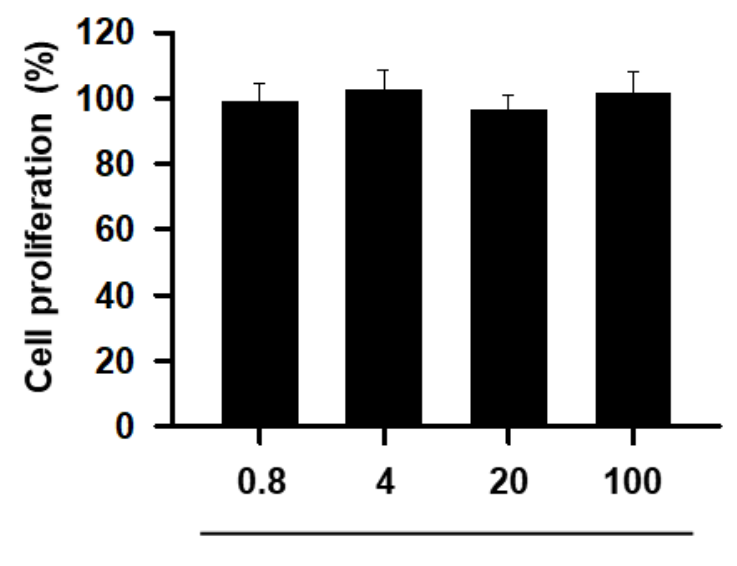

Formicin $\mathrm{A}(\mu \mathrm{M})$

Table S1. Effect of formicins A-C (1-3) on the cell viability of breast cancer cells (MDAMB-231) and human normal lung fibroblast cells (MRC-5).

\begin{tabular}{cccc}
\hline \multicolumn{2}{c}{ Cell line } & MDA-MB-231 & MRC-5 \\
\hline & Formicin A & 48.9 & $>100$ \\
IC $_{50}$ & Formicin B & $>100$ & $>100$ \\
$(\mu \mathrm{M})$ & Formicin C & $>100$ & $>100$ \\
& & 3.64 & 14.7 \\
\hline
\end{tabular}

aEtoposide was used as a positive control.

\section{References}

(1) Li, Y.; Zhang, W.; Zhang, H.; Tian, W.; Wang, S.; Zheng, M.; Zhang, J.; Sun, C.; Deng, Z.; Sun, Y.; Qu, X.; Zhou, J. Angew. Chem. Int. Ed. 2018, 57, 5823-5827.

(2) Kusebauch, B.; Brendel, N.; Kirchner, H.; Dahse, H.-M.; Hertweck, C. ChemBioChem 2011, 12, 2284-2288.

(3) Vichai, V.; Kirtikara, K. Nat. Protoc. 2006, 1, 1112-1116.

(4) Byun, W. S.; Kim, W. K.; Han, H. J.; Chung, H.-J.; Jang, K.; Kim, H. S.; Kim, S.; Kim, D.; Bae, E. S.; Park, S.; Lee, J.; Park, H.-G.; Lee, S. K. Mol. Ther.-Oncolytics 2019, 15, 140-152. 